\title{
Using Treasury STRIPS to Measure the Yield Curve *
}

\author{
Brian Sack \\ Division of Monetary Affairs \\ Federal Reserve Board of Governors \\ Washington, D.C. 20551 \\ brian.p.sack@frb.gov
}

October 2000

\begin{abstract}
Treasury STRIPS derived from coupon payments of notes and bonds provide an effective reading of the zero-coupon yield curve. Among their advantages, coupon STRIPS are zerocoupon securities and have a complete range of maturities. Moreover, the fungibility of coupon STRIPS appears to remove some of the idiosyncratic variation in the yields of individual Treasury notes and bonds, so that the coupon STRIPS yield curve is relatively smooth. Yields on coupon STRIPS are compared to the zero-coupon yield curves derived from notes and bonds under the Nelson-Siegel method and the Fisher-Nychka-Zervos method. The results point to some shortcomings of these approaches and indicate that the zero-coupon yield curve could be estimated more precisely from coupon STRIPS.
\end{abstract}

\footnotetext{
${ }^{*}$ I wish to thank James Clouse and Vincent Reinhart for valuable comments, and Ian Anderson for exceptional research assistance and feedback. The opinions expressed are those of the authors and do not necessarily reflect the views of the Board of Governors of the Federal Reserve System or other members of its staff.
} 


\section{Introduction}

The market for Treasury STRIPS, which are zero-coupon securities created from the coupon and principal payments of Treasury notes and bonds, has grown into a large market that is highly integrated with the market for notes and bonds. ${ }^{1}$ As of January 1999, nearly 35 percent of all outstanding bonds were held in stripped form, and the total amount of STRIPS outstanding at that time exceeded $\$ 200$ billion. Because investors can quickly and (almost) costlessly transform their holdings of notes and bonds into STRIPS and vice-versa, there are sizable flows across the two markets. Over 1998, for example, nearly $\$ 20$ billion of Treasury securities were either stripped or reconstituted every month.

This paper investigates the potential use of Treasury STRIPS, and in particular those STRIPS derived from coupon payments, for measuring the zero-coupon Treasury yield curve. The findings indicate that these "coupon STRIPS" provide an effective reading of the zero-coupon Treasury yield curve. Among their advantages for this purpose, coupon STRIPS are already in the form of zero-coupon securities and have a full range of maturities. An additional advantage is that coupon STRIPS are fungible - that is, the coupon payments from different underlying securities are interchangeable - so that they are typically not affected by the variation in any single underlying security. As a result, coupon STRIPS form a fairly smooth yield curve.

The yields on coupon STRIPS are compared with zero-coupon yield curves estimated from Treasury notes and bonds under two widely used approaches. The first approach is the NelsonSiegel method, which imposes a considerable amount of structure on the shape of forward rates to derive a parsimonious model of the yield curve. The STRIPS yields indicate that one of the assumptions underlying the Nelson-Siegel method, that forward rates asymptote to a constant level, is consistently violated.

The second approach is the Fisher-Nychka-Zervos (FNZ) method, which (as applied in this paper) allows much more flexibility in the shape of forward rates and hence the yield curve. The zero-coupon curve derived from notes and bonds under the FNZ method is fairly effective at capturing the overall shape of the yields on coupon STRIPS. However, at times there are considerable differences at intermediate maturities, where there are few notes and bonds available for estimating the yield curve. In fact, the lack of securities in that maturity range, in combination with the premiums found on some individual notes and bonds, can generate very erratic patterns in the estimated yields and forward rates that are inconsistent with the STRIPS data.

Considering these difficulties, the paper explores an alternative approach of estimating the yield curve directly from the STRIPS data using the Fisher-Nychka-Zervos method. The results indicate that the zero-coupon curve derived from coupon STRIPS has a smoother shape and is estimated more precisely than that derived from notes and bonds. Overall, these findings strongly indicate that coupon STRIPS provide valuable information about the zero-coupon Treasury yield curve and can be effectively used in estimating that curve.

\footnotetext{
${ }^{1}$ STRIPS is an acronym for Separate Trading of Registered Interest and Principal of Securities.
} 


\section{The Market for Treasury STRIPS}

The Treasury STRIPS program allows an investor to split a Treasury note or bond into a series of zero-coupon securities, one corresponding to each coupon payment and the principal payment of the underlying security. For example, stripping a thirty-year bond would generate sixty-one individual zero-coupon securities: sixty "coupon STRIPS" maturing every six months to the maturity date of the bond, and one "principal STRIP" maturing on the maturity date of the bond. The final coupon STRIP and principal STRIP are treated as distinct securities (they are given different CUSIP numbers), despite having identical maturity dates. In fact, there is an important difference between coupon and principal STRIPS. Coupon STRIPS are fungible, so that coupon STRIPS from different securities with the same payment dates are assigned the same CUSIP number. Principal STRIPS instead remain specifically identified with the security from which they were stripped, even if they have identical payment dates as other STRIPS.

Since January 1987, investors have also been able to reconstitute notes and bonds from their stripped components. To reconstitute a given Treasury security, the investor needs to obtain a portfolio of STRIPS corresponding to all of the payments of the particular security. Again, the coupon payments from the security instead could have originated from any security with coupon payments on those dates, while the principal STRIP has to be the one that was derived from that specific security.

All ten-year notes and all bonds issued after November 1984 are eligible to be stripped. The program was expanded in September 1997 to include newly issued Treasury notes of all maturities. Eligible securities must be held in book-entry form to be stripped, which allows the transaction to be executed at very little cost. A depository institution initiates the transaction by sending a Fedwire message to the Federal Reserve Bank of New York, which then converts the security to the corresponding STRIPS in the owner's account under the book entry system. The quantity of Treasury securities to be stripped must be a multiple of the packet size, which is the minimum amount of the Treasury security for which all stripped components are in $\$ 1000$ increments. ${ }^{2}$ The stripping or reconstituting transaction typically takes about 30 minutes and involves a fee of $\$ 25$, which is trivial relative to the magnitude of a typical stripping transaction.

The STRIPS program emerged as a result of the considerable interest that investors showed in zero-coupon Treasury securities, which was in fact evident long before the advent of the STRIPS program. In the early 1980's, several investment banks began holding Treasury securities with a custodian in special trust accounts and themselves selling the various components of the securities to investors. Over $\$ 50$ billion of zero-coupon securities were created in this manner from 1982 to 1984, including, among others, TIGRs issued by Merrill Lynch and LIONs issued by Lehman Brothers. Following the implementation of the STRIPS program in January 1985, the market for zero-coupon Treasury securities expanded even more strongly, as the program allowed investors to create and trade zero-coupon securities more easily and at a lower cost. As a result, Treasury

\footnotetext{
${ }^{2}$ Because coupon rates range in steps of $1 / 8 \%$, packet sizes can reach as high as 1600 .
} 
Table 1: Stripping Activity

Millions of dollars

\begin{tabular}{|c|c|c|c|c|c|c|}
\hline & \multicolumn{4}{|c|}{ 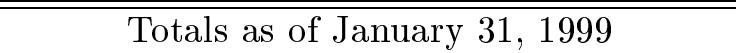 } & \multicolumn{2}{|c|}{ 1998 Monthly Average } \\
\hline Original & Total & & Not & Percent & Gross & Gross \\
\hline Maturity & Issued & Stripped & Stripped & Stripped & Stripping & Reconst. \\
\hline 2-yr Note & 260,770 & 722 & 260,048 & 0.3 & 0 & 0 \\
\hline 3 -yr Note & 38.721 & 0 & 38.721 & 0.0 & 0 & 0 \\
\hline 5-yr Note & 154,516 & 342 & 154.174 & 0.2 & 0 & 0 \\
\hline 10-yr Note & 475,526 & 57,353 & 418,173 & 12.1 & 932 & 899 \\
\hline 20-yr Bond & 23,706 & 8,987 & 14,719 & 37.9 & 616 & 79 \\
\hline 30-yr Bond & 440,448 & 153,861 & 286,587 & 34.9 & 12,572 & 6,929 \\
\hline Total & $1,393,687$ & 221,265 & $1,172,422$ & 15.9 & 14,120 & 7,907 \\
\hline
\end{tabular}

STRIPS quickly came to dominate the market for zero-coupon Treasury securities.

As of January 1999, the total amount of STRIPS outstanding stood at over $\$ 221$ billion. $^{3}$ As shown in Table 1, stripping activity is not evenly distributed across securities: about $35 \%$ of bonds were held in stripped form at that time, compared to about $12 \%$ of ten-year notes and hardly any for shorter-term notes. ${ }^{4}$ Stripping activity has been concentrated on longer-dated Treasury securities for several reasons. First, stripping longer-term securities allows investors to obtain securities with longer duration than coupon-bearing Treasury securities, an appealing characteristic to some investors. For example, the duration of a thirty-year bond with a 6 percent coupon has a duration just over fourteen years, while stripping that security creates zero-coupon securities with duration reaching thirty years. Second, stripping longer-term bonds creates zero-coupon securities with a full array of maturities out to the maturity of the underlying bond, so that stripping activity in shorter-dated securities only creates additional supply of already available zero-coupon securities.

The table also reports the gross flows observed between STRIPS and the underlying Treasury securities over 1998. The market is characterized by heavy flows of gross stripping and reconstitution activity, with an average of over $\$ 22$ billion of securities either stripped and reconstituted each month over 1998. While the gross flows of stripping and reconstitution are large, these flows offset one another to a large extent. In fact, the total amount of STRIPS outstanding has not changed considerably since 1994 .

Because long-term bonds are typically issued on a quarterly basis, the stripping of these instruments has created a supply of STRIPS maturing at the middle of every quarter out to fairly long maturities, as shown in Figure 1. Because each stripped security has an even flow of coupon payments, the amount of outstanding coupon STRIPS is fairly evenly distributed, with about $\$ 13$ billion of these securities maturing each year ( $\$ 3.25$ billion per quarter). The supply of coupon STRIPS only begins to drop off at long maturities, beyond which there are few stripped bonds. In

\footnotetext{
${ }^{3}$ The amount of outstanding STRIPS is reported in the Monthly Statement of the Public Debt that is published by the Treasury.

${ }^{4}$ Only nominal securities are included. Treasury Inflation-Indexed Securities are also eligible for the STRIPS program, but there has been no stripping activity in these securities.
} 
contrast to the even distribution of coupon STRIPS, the maturity distribution of principal STRIPS more closely reflects the distribution of the underlying Treasury securities, shown in the bottom panel. At maturity years through 2008, the amount of outstanding, unstripped notes and bonds far exceeds the amount of STRIPS outstanding, reflecting the larger, more frequent issuance of shorter-term securities which are not stripped. However, the distribution of unstripped notes and bonds is much more variable across maturities. Of particular note, there is a large gap in the maturity structure of non-callable notes and bonds, with no securities maturing between 2009 and 2014. This gap, which arises because the Treasury issued twenty-year bonds and callable securities before shifting to non-callable thirty-year bonds in 1985, can have an important impact on the estimation of the yields curve, as seen below.

\section{Yields on Treasury STRIPS}

This section investigates the pricing of STRIPS. The findings suggest that coupon STRIPS may provide an effective reading of the zero-coupon Treasury yield curve.

\subsection{The Pricing of STRIPS Relative to Notes and Bonds}

The significant flows between the markets for coupon-bearing Treasury securities and STRIPS suggests that these markets are highly integrated. Arbitrage across the two markets should keep the price of a Treasury note or bond nearly equal to the price of a portfolio of STRIPS that could be created from or reconstituted into that security. The relevant arbitrage strategies, and the cost of the strategies as determined by the bid-offer spreads, are depicted in the diagram below. If the price of the note or bond is sufficiently low relative to the portfolio of corresponding STRIPS, there would be an arbitrage opportunity in purchasing the Treasury, stripping it, and selling the components. This strategy would be profitable if the difference in the bid prices (which are used in the analysis below) were greater than the bid-offer spread on the note or bond. Conversely, if the note or bond were sufficiently rich relative to its corresponding STRIPS, an investor could purchase the STRIPS, reconstitute the Treasury security, and sell it, which would be profitable if the difference in the bid prices were greater than the bid-offer spread on the portfolio of STRIPS. ${ }^{5}$ These arbitrage strategies should keep the value of the STRIPS portfolio within a fairly tight range of the price of the Treasury security, with the width of that range determined by the relevant transactions costs.

To investigate this pricing relationship, we compare the price of strippable Treasury securities to the value of the portfolio of their stripped components. Bid-side quotes as of 3:15 p.m. were collected for all outstanding Treasury notes and bonds and for all coupon and principal STRIPS maturing in the middle of the quarter. ${ }^{6}$ Because nearly all outstanding STRIPS mature in the

\footnotetext{
${ }^{5}$ Of course, each STRIPS security in the portfolio has its own bid-offer spread. For simplicity, the discussion focuses on the bid-offer spread on the entire portfolio.

${ }^{6}$ The data on notes and bonds were compiled by the Federal Reserve Bank of New York, and the data on STRIPS were obtained with special permission from Goldman Sachs. Although neither source of data is publicly available,
} 


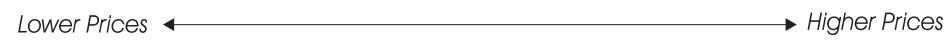

Stripping Arbitrage

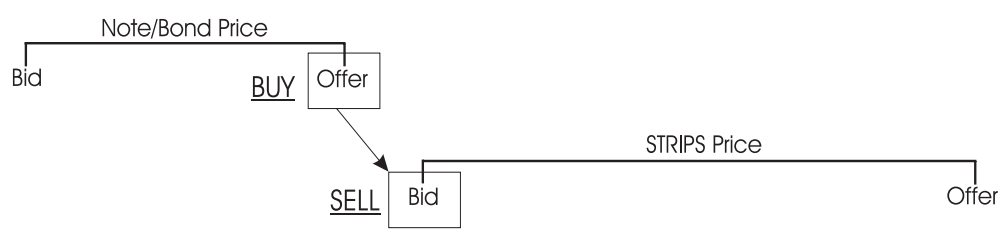

Reconstitution Arbitrage

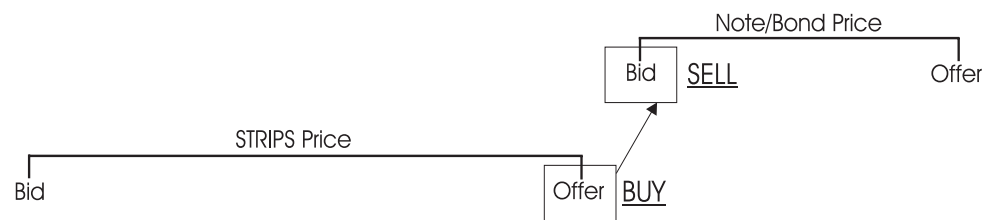

middle month of the quarter, our database is limited to those securities, and so the analysis in this section will focus only on those Treasury securities issued at mid-quarter refundings. The data are daily and range from January 1994 through January 1999. Earlier dates have been excluded out of concern about the reliability of the data and the observation that the amount of outstanding STRIPS was growing rapidly before that time, suggesting that the market may have still been in a developmental stage.

Using these data, we replicate all strippable Treasury notes and bonds over this period with their corresponding portfolios of STRIPS, for a total of 57,084 observations. ${ }^{7}$ Figure 2 shows the distribution of the percentage deviations between the price of the note or bond and the value of the corresponding portfolio of STRIPS. The distribution is fairly tight, with the difference in prices within two tenths of a percentage point for almost all of the observations.

The tight pricing relationship indicates that the arbitrage opportunities between coupon-bearing Treasury securities and the reconstitutable portfolio of STRIPS are limited. ${ }^{8}$ Indeed, most of the price differences likely fall within the range of transactions costs. Bid-offer spreads for off-the-run notes and bonds vary across different securities but are typically below $2 / 32(\$ 0.06)$ per $\$ 100$ face value. Under that transaction cost, about $15 \%$ of the observations present a stripping arbitrage opportunity. Bid-offer spreads are somewhat wider for STRIPS securities and vary considerably, so that the bid-offer spread on the STRIPS portfolio will depend on the security being reconstituted. However, even if the bid-offer spread were as narrow as 4/32 (\$0.13) for the STRIPS portfolio, only about $5 \%$ of the observations would present a reconstitution arbitrage opportunity. ${ }^{9}$

similar data are reported in the Wall Street Journal.

${ }^{7}$ We exclude the one callable Treasury bond that can be stripped.

${ }^{8}$ This arbitrage relationship is also investigated by Jordan, Jorgensen, and Kuipers (2000), who find limited arbitrage opportunities as well. That study also finds that most arbitrage opportunities disappear quickly, typically within two days.

${ }^{9}$ STRIPS are quoted in terms of yields, rounded to the nearest tenth of a basis point. Thus, the bid-offer spread 
Some of these arbitrage opportunities may simply represent "noise" that arises in our data set. In particular, the quotes on strippable Treasury securities and STRIPS are taken from different dealers and are reported by different sources. ${ }^{10}$ In addition, actual transactions costs could exceed the rough estimates in many cases, thus giving the appearance of arbitrage opportunities. Finally, some of the differences in the relative prices may be attributed to a slight difference in the taxation of these instruments, although this seems to have a trivial effect judging from discussions with market participants. ${ }^{11}$

Overall, there appears to be little segmentation between the STRIPS market and the market for notes and bonds. There are considerable flows between the markets as investors strip and reconstitute notes and bonds. Moreover, a reconstitutable portfolio of STRIPS is valued very closely to the price of the underlying Treasury security, which is not surprising given investors' ability to arbitrage across the two markets.

\subsection{Coupon versus Principal STRIPS: The Importance of Fungibility}

One interesting characteristic of the STRIPS market is that large differences can arise in the yields of coupon and principal STRIPS with the same maturity date, even though these securities offer identical payments. This is evident in the top panel of Figure 3, which shows the yields on coupon and principal STRIPS on December 15, 1998. In the most extreme example on this date, labeled "A", the yield on the principal STRIP is 32 basis points below that of the coupon STRIPS with the same maturity.

These differences in yields likely result from the distinction between the securities - that coupon STRIPS are fungible, while principal STRIPS remain specifically identified with the security from which they were derived. ${ }^{12}$ In fact, fungibility has powerful implications for the pricing of STRIPS. Because a principal STRIP can only be created by stripping a particular note or bond and is needed to reconstitute that particular security, the price of the principal STRIP is closely linked to the price of that particular underlying Treasury security. By contrast, because coupon STRIPS maturing on the same day but originating from different stripped securities are treated as the same security, coupon STRIPS should not be influenced by any behavior specific to a single underlying security. Instead, the coupon STRIP should be determined by the value of a cash payment on the maturity date as reflected in the prices of a wide range of securities.

Indeed, the lower yield of the principal STRIP labeled "A" reflects a considerable premium on

for STRIPS is typically expressed in basis points. Here I have converted it to prices for comparison to notes and bonds.

${ }^{10}$ In addition, the quotes on notes and bonds assume next day settlement, while the STRIPS quotes assume two-day settlement. This difference introduces a slight discrepancy that cannot be corrected.

${ }^{11}$ The coupon interest of conventional Treasury securities is taxed, along with a portion of the anticipated capital gains or losses on the security. Since STRIPS pay no coupons, STRIPS are taxed as original issue discount securities under which the gains in the price of the security are amortized assuming a constant yield to maturity. This difference makes it more advantageous to hold STRIPS as yields rise and as the yield curve steepens, as described in more detail in Livingston and Gregory (1989).

${ }^{12}$ Daves and Ehrhardt (1993) investigate the impact of liquidity and fungibility on the difference between coupon and principal STRIPS prices. 
the underlying Treasury bond, as shown in the lower panel. In this case the underlying bond, also labeled "A", was the cheapest-to-deliver into the CBOT Treasury futures contract, which caused that security to trade at a much lower yield than other securities with comparable maturity. (This and other sources of idiosyncratic variation in Treasury yields are discussed in section 5.) While this effect passed through to the principal STRIP, the coupon STRIP maturing that day was largely unaffected, remaining in line with the yields on surrounding securities.

Similar behavior is observed over the entire sample. Figure 4 shows the actual amount by which the prices of principal STRIPS deviated from coupon STRIPS with identical maturity dates over the sample, plotted against the amount by which the principal STRIPS would need to deviate in order to match the price of the underlying Treasury note or bond. The figure shows a strong positive relationship, suggesting that the price of the principal STRIP often adjusts away from that of the coupon STRIP to reflect the price of the underlying security (specifically, to maintain the tight pricing relationship between the underlying Treasury and the portfolio of corresponding STRIPS that was shown in Figure 2). The tail of the distribution shooting out to the right is in fact the cheapest-to-deliver premium around the time shown in Figure 3, when this premium was unusually large (as discussed below).

Judging from these findings, fungibility presents an important advantage for estimating the yield curve from coupon STRIPS, in that the shape of the coupon STRIPS yield curve should not be strongly influenced by various factors that are specific to individual underlying Treasury securities. This and other advantages to using coupon STRIPS to measure the yield curve are discussed in the next section.

\subsection{The Coupon STRIPS Yield Curve}

As was apparent from Figure 3, the raw quotes on coupon STRIPS provide a reading of the zerocoupon yield curve. There are several advantages to using coupon STRIPS for that purpose, based on the characteristics of the market highlighted in previous sections. First, these securities are already in the form of zero-coupon securities, so that their yields provide a direct reading of the zero-coupon yield curve. Second, as discussed in section 2, there is a full range of Treasury coupon STRIPS maturing every three months out to maturities beyond twenty-eight years, without the gap across the maturities of notes and bonds. Third, the fungibility of coupon STRIPS appears to eliminate some of the variation in yields arising from factors that are idiosyncratic to particular Treasury securities. And finally, the STRIPS market appears highly integrated with the remainder of the Treasury market.

In general, the coupon STRIPS yield curve shown in Figure 3 has a very reasonable shape. An increasing risk premium tends to make it upward sloping. In addition, the yield curve appears to have significant curvature, as yields peak at maturities around twenty years and then gradually turn down. This curvature most likely reflects the "convexity premium" that results from the volatility of yields. This premium arises because the capital gain resulting from a decline in the yield is 
greater in magnitude than the capital loss from an equal-sized increase in the yield. As a result, (symmetric) uncertainty about future yields tends to increase the expected return on a Treasury security for a given level of its yield, allowing the yield to be lower than otherwise. The magnitude of this effect tends to increase with the security's maturity, thus adding curvature to the shape of the yield curve.

Although the coupon STRIPS yield curve appears to have a reasonable shape, one potential shortcoming of restricting the analysis to coupon STRIPS is that there is a somewhat limited supply of each issue. In particular, as shown earlier in Figure 1, there was less than $\$ 4$ billion of coupon STRIPS maturing each quarter as of January 1999. The limited supply of coupon STRIPS could potentially hinder their liquidity. Anecdotal reports suggest that liquidity in the STRIPS market is comparable to that of off-the-run notes and bonds, except possibly for coupon STRIPS with shorter maturities. The most liquid portion of the coupon STRIPS market is between maturities of ten and twenty-five years. In fact, dealers estimate that as much as $80 \%$ of trading volume in STRIPS takes place in securities with more than ten years to maturity.

Indeed, liquidity among shorter-term STRIPS is of some concern. Some individual STRIPS issues with maturities less than ten years have very concentrated holdings, in part due to inelastic institutional demand for zero-coupon securities at these shorter maturities. ${ }^{13}$ In fact, some individual STRIPS are difficult to obtain in the market. Dealers may only be willing to sell those securities at considerable premiums, pushing their yields well below those on other STRIPS with comparable maturities. This effect is apparent in the STRIPS yields shown in Figure 3. While most STRIPS yields line up to form a smooth yield curve, several of these securities were instead trading at yields well below the curve, particularly the security labeled "B". ${ }^{14}$ However, despite some idiosyncratic variation in the yields of shorter-term securities, the yields on coupon STRIPS in general appear to offer an effective reading of the zero-coupon yield curve.

\section{Estimating the Zero-Coupon Yield Curve}

A widespread practice among market participants and researchers is to estimate the zero-coupon Treasury yield curve from off-the-run notes and bonds. Given that coupon STRIPS appear to provide an effective reading of the zero-coupon curve, we can use their yields to evaluate various approaches that are taken. This section makes this comparison for two widely used methods for deriving the zero-coupon curve, which are based on Nelson and Siegel (1987) and Fisher, Nychka, and Zervos (1995). According to a recent study by the BIS (1999), all of the central banks reporting

\footnotetext{
${ }^{13}$ For example, municipalities engaging in defeasance trades often seek to hold zero-coupon securities with particular maturity dates. In a defeasance trade, a municipality can refinance outstanding debt before its call date by issuing new debt and using the proceeds to purchase (in escrow) Treasury securities that will be used to retire the previouslyissued debt on its call date. In this case, there is no need for a stream of coupon payments, so the municipality will have a fairly inelastic demand for the zero maturing near the call date.

${ }^{14}$ I appreciate helpful discussions with STRIPS traders and analysts at Goldman Sachs, Merrill Lynch, Paine Webber, and J.P Morgan for some of these insights.
} 
yield curve estimates to the BIS use one of those two methods. ${ }^{15}$

To understand these approaches, it is useful to first consider the yields on all outstanding noncallable Treasury notes and bonds, which were previously shown in Figure 3 for a recent date. Of the 164 individual issues outstanding on that date, the greatest concentration of securities is at maturities of less than five years, in part because short-term securities are issued more frequently. In addition, the gap between securities maturing in ten to fifteen years described earlier is evident.

Each coupon-bearing security can be thought of as a portfolio of zero-coupon securities, one for each of its coupon and principal payments. The price of the note or bond should equal the value of that portfolio:

$$
P_{t}^{N}=\sum_{i=1}^{2 N} C \cdot d(i / 2, t)+V \cdot d(N, t),
$$

where $P_{t}^{N}$ is the price of the $N$-year security at time $t, C$ is its coupon payment, $V$ is its principal payment, and $d(i, t)$ is the discount function, which measures the value of a zero-coupon security maturing in $i$ years at time $t$. The discount function is determined by the yields on the zero-coupon securities as follows:

$$
d(i, t)=\exp (-y(i, t) \cdot i)
$$

where $y(i, t)$ is the zero-coupon yield maturing in $i$ years at time $t$ measured under continuous compounding. Forward rates are related to these zero-coupon yields by the following relationship:

$$
y(i, t)=1 / i \cdot \int_{0}^{i} f(i, t)
$$

where $f(i, t)$ is the instantaneous forward rate $i$ years ahead at time $t$. A zero-coupon yield curve (and implied forward rate schedule) can therefore be estimated to best match the prices of the coupon-bearing securities.

Note, however, that the yields on notes and bonds do not fully identify the zero-coupon yield curve unless some additional assumptions about the functional form of that curve are imposed. For example, suppose that the price of the sixteen-year zero-coupon security was increased by $\$ 1$ and that of the seventeen-year zero-coupon security was decreased by $\$ 1$. Given the maturity gap, this change would currently have no impact on the price of any outstanding note or bond, as all securities affected place equal weighting on those two zeros (equal to their coupon payments). Indeed, notes and bonds can only be used to identify the zero-coupon curve if some structure is imposed on that curve. This structure typically takes the form of some smoothness criterion for the prices of the zero-coupon securities, their yields, or the implicit forward rates. The two approaches considered here both impose some smoothness on the forward rates.

\footnotetext{
${ }^{15}$ As reported in BIS (1999), Belgium, Canada, Finland, France, Germany, Italy, Norway, Spain, Sweden, and the United Kingdom all use the Nelson-Siegel method or a modification of that method developed by Svensson, while Japan and the United States use the Fisher-Nychka-Zervos method.
} 


\subsection{The Nelson-Siegel Method}

A popular approach for estimating the zero-coupon yield curve is based on Nelson and Siegel (1987). One of the primary advantages of this approach is that it is a very parsimonious specification, although one that still allowing a fairly rich set of shapes. Specifically, the Nelson-Siegel approach assumes that forward rates are described by the following equation:

$$
f(i, t)=\beta_{0}+\beta_{1} \cdot \exp (-i / \tau)+\beta_{2} \cdot i / \tau \cdot \exp (-i / \tau),
$$

which is a function of four parameters: $\beta_{0}, \beta_{1}, \beta_{2}$, and $\tau$. These parameters are typically allowed to vary period-by-period. ${ }^{16}$ Under this specification, forward rates begin at the rate $\beta_{0}+\beta_{1}$, can have a "humped" shape, and eventually asymptote to the constant level $\beta_{0} .{ }^{17}$ Zero-coupon yields also asymptote to the constant level $\beta_{0}$ under this specification.

The forward rate schedule can be used to compute the predicted prices of Treasury notes and bonds using equations (1) to (3). The parameters from equation (4) are estimated to minimize the deviations between these predicted prices and the observed prices of Treasury notes and bonds at any point in time. Following the practice of most central banks in the BIS study, we use weighted non-linear least squares, where the weights are proportional to the inverse of the maturity of the security. Three snapshots of the results from this method are shown in Figure 5, which shows the estimated zero-coupon curves plotted along with the quotes on coupon STRIPS. ${ }^{18}$ Overall, the yield curves and forward rates are quite smooth as a result of the structure that this approach imposes.

However, one of the assumptions of the Nelson-Siegel method is violated by the STRIPS data: STRIPS yields typically begin to decline at long maturities, which is inconsistent with the assumption that yields and forward rates asymptote to a constant level. ${ }^{19}$ In fact, this characteristic is prevalent throughout the sample. Over the sample, the peak of the STRIPS yield curve has ranged between maturities of 17 and 25 years, with the peak taking place at about $22 \frac{1}{2}$ years on average. Moreover, the decline in the STRIPS yield curve from its peak to the longest maturity has averaged about -17 basis points, with $95 \%$ of the observations having a decline of at least -8 basis points. ${ }^{20}$

The curvature in the coupon STRIPS yield curve likely results from the convexity premium, as discussed above. The Nelson-Siegel method, by imposing a constant asymptote for yields and forward rates, does not allow for this effect. Thus, yields on coupon STRIPS point to a possible shortcoming of the Nelson-Siegel method. Of course, any specification relying on such a small

\footnotetext{
${ }^{16}$ For this reason the forward rates are a function of $t$. Time subscripts have been left off of the parameters for notational simplicity.

${ }^{17}$ Svensson (1994) extended this specification to make it more flexible, allowing a second hump by adding two parameters to the forward rate specification.

${ }^{18}$ In all figures, the estimated yield curves have been converted from continuous compounding to a bond-equivalent basis.

${ }^{19}$ Of course, yields under the Nelson-Siegel mehtod are not forced to converge to the asymptote within thirty years. However, if the hump is found to be too far out the yield curve, the specification would have a very difficult time estimating the parameter $\beta_{0}$.

${ }^{20}$ The longest maturity is considered to be the twenty-eight-year security, as there is little supply of STRIPS maturing beyond that point.
} 
number of parameters is going to have some difficulty fitting the entire yield curve, and thus this shortcoming must be weighed against the advantages of having a parsimonious approach.

\subsection{The Fisher-Nychka-Zervos Method}

An alternative methodology for estimating the zero-coupon yield curve is that developed by Fisher, Nychka, and Zervos (1995). The Fisher-Nychka-Zervos method assumes that the forward rate schedule is described by a spline with a large number of parameters, giving it lots of flexibility. However, the FNZ method imposes some smoothness by specifying a penalty on the variation of the forward rates, equal to the integral of the second derivative of the forward rate schedule. The parameters of the spline are estimated to minimize a weighted average of the summed deviations between the observed and predicted prices of notes and bonds and the smoothness penalty. The weight assigned to the smoothness penalty is optimally determined using a method referred to as "generalized cross validation" (GCV). Given an exogenous parameter $\theta$ that determines the preference for smoothness in forward rates, the GCV procedure essentially allows for more flexibility in forward rates only to the extent that it is warranted by the data. ${ }^{21}$

This methodology underlies the zero-coupon yield curve estimated at the Federal Reserve Board, as described in Fisher (1996). Following their approach, all securities are weighted equally in the estimation, and the smoothness parameter is set to $\theta=2$. In addition, the two most recently issued securities or each maturity class are excluded from the sample, for reasons discussed below.

Figure 6 shows three snapshots of the results using the FNZ method, where the zero-coupon yield curves are compared to the yields on the coupon STRIPS securities, as in Figure 5. The estimated zero-coupon yield curves are fairly effective at capturing the overall shape of the STRIPS yields, at least in the upper and lower panels. In particular, the estimated yield curves match shorter-term STRIPS quite well and also capture the tendency for the STRIPS yields to gradually turn down at longer maturities.

While the additional flexibility allowed under the FNZ method improves the fit of the estimated yield curve relative to the Nelson-Siegel method, this flexibility also can lead to some difficulties. These difficulties are dramatically apparent in the middle panel. On that date, the estimated yield curve dips considerably at intermediate maturities, generating very erratic movements in forward rates, which fall below 4 percent after ten years, only to then rise above 9 percent after fifteen years, before again declining sharply and even turning negative at long maturities. Although less dramatic, similar dips in yields at intermediate maturities and variation in forward rates are also apparent in the upper and lower panels.

This variation is investigated more closely in Figure 7, which shows the actual yields on all Treasury notes and bonds on December 15, 1998, the estimated zero-coupon yield curve, and the yields for the notes and bonds predicted from the estimated curve. The considerable variation in the estimated yield curve at intermediate maturities results primarily from the lack of data

\footnotetext{
${ }^{21}$ For additional details on the methodology, see Fisher, Nychka, and Zervos (1995). To implement this method, we use the Mathematica software package described in Fisher and Zervos (1996).
} 
in that maturity range. The maturity gap is particularly problematic on that date because of various idiosyncratic factors affecting the yields of particular Treasury securities. The yields on the securities to the right of the maturity gap were pushed down by a premium for being the cheapestto-deliver into the futures contract. At the same time, the securities to the left of the maturity gap, which are recently issued ten-year notes, were also trading at yields below the rest of the yield curve, owing to a premium for their greater liquidity. The yield curve therefore dips down in an attempt to match these lower yields, with nothing to guide it in between except the smoothness objective. Becuase that dip would lower the yields on all longer-dated Treasury securities, the yield curve (and forward rates shown in Figure 6) has to increase sharply between twelve and fifteen years to offset that effect.

Thus, factors that are specific to individual Treasury securities apparently had a significant impact on the shape of the estimated yield curve on this date. In general, as seen by the hollow squares in the figure, there is considerable dispersion of Treasury yields around the levels predicted by the estimated yield curve. In part, this dispersion reflects various idiosyncratic factors that can influence the yields of individual notes and bonds. Section 5 describes various sources of idiosyncratic variation in Treasury yields in greater detail, including the premiums for greater liquidity and for deliverability into futures contracts mentioned above, and provides a measure of the impact of each.

Among the most troublesome of these idiosyncratic factors are the liquidity premiums on recently issued Treasury securities. In the current example, these liquidity premiums affect not only the dip at intermediate maturities, but also the drop off at the very long end of the yield curve and forward rate schedules, which is affected by recently issued thirty-year bonds. Most practitioners recognize the liquidity premiums on these securities and exclude the on-the-run (the most recently issued) security from each maturity class from their samples. ${ }^{22}$ Indeed, the results presented exclude the on-the-run and the first off-the-run (the second most recently issued) securities from each maturity class. However, some impact of the liquidity premium is still evident, as the liquidity premium often works its way into several off-the-run issues. Figure 8 explores the effect of excluding recently issued securities. The overall shape of the yield curve and forward rate schedule depends importantly on the number of securities that are excluded. As additional securities are dropped, the variation in forward rates continues to diminish. However, deciding how many securities to exclude is somewhat arbitrary, and the extent of the liquidity premium, both in terms of size and the number of securities affected, can vary over time, making that decision difficult.

Of course, an alternative for avoiding excessive variation is to impose additional structure on the shape of the yield curve and forward rates. Under the FNZ methodology, this involves increasing the parameter $\theta$ measuring the preference for smoothness. Alternatively, a more restrictive functional form could be assumed, such as a cubic spline with a more limited number of knot points. However, while this may help remove some of the variation in the results, it will likely come at the expense

\footnotetext{
${ }^{22}$ Alternatively, practitioners might be interested in estimating an on-the-run yield curve and include only those issues. This paper is concerned with estimating an "off-the-run" yield curve.
} 
of fitting other parts of the yield curve less well. Indeed, this is precisely what is found under the Nelson-Siegel specification shown above.

Overall, while the date highlighted in Figure 7 is admittedly an extreme example, it highlights the difficulties involved in estimating the zero-coupon curve from notes and bonds. The results suggest that the gap across maturities, in combination with various factors affecting the yields of individual Treasury securities, can at times generate variability in the zero-coupon yield curve and in forward rates. Moreover, the problem is not limited to several extreme dates. Even in the upper and lower panels of Figure 6, the largest deviations between the estimated yield curve and the actual STRIPS yields were found at intermediate maturities, suggesting that these issues consistently present difficulties in estimating the yield curve under rather flexible methods.

\subsection{Estimating the Yield Curve from Coupon STRIPS}

The analysis above uses raw STRIPS quotes to assess the zero-coupon yield curves estimated from notes and bonds. An alternative approach is to estimate the zero-coupon yield curve directly from the STRIPS quotes, as explored in this section. In the results that follow, the zero-coupon yield curve is estimated from quotes on coupon STRIPS using the FNZ methodology described above. ${ }^{23}$ In doing so, STRIPS with more than twenty-eight years to maturity are discarded, as there are only small amounts of those securities outstanding (see Figure 1). The results are then compared to the yield curve estimated from notes and bonds under the same methodology.

The top right panel of Figure 9 shows the STRIPS yield curve estimated for a recent date. Because the raw STRIPS quotes themselves form a rather smooth yield curve, the estimated yield curve essentially draws a line directly through those quotes. An advantage to using the estimated curve is that it smoothes through some of the variation in individual STRIPS that was discussed above. Note, however, that these idiosyncratic effects do not have a dramatic impact on the shape of the yield curve and forward rates, unlike the findings above for Treasury notes and bonds. One reason is that the idiosyncratic premiums on notes and bonds interacted with the gap in their maturity distribution, while there is no similar maturity gap for STRIPS.

The middle panels of the figure show the yield curves estimated from STRIPS and from notes and bonds (N/B) with two-standard error bands, and the bottom panels similarly show implied forward rates. The estimated yield curve and corresponding forward rates vary to a much smaller extent than those estimated from Treasury notes and bonds. In fact, the dip at intermediate maturities is virtually eliminated by using the STRIPS quotes.

In addition to their smoother shapes, the STRIPS yield curve and forward rate schedule are estimated more precisely than those based on notes and bonds. The standard errors of these curves on this date are plotted across all maturities in Figure 10. In general, the standard errors for the zero-coupon yields are much higher for the N/B estimates than for the STRIPS estimates. The standard error of the N/B estimates are particularly elevated at intermediate maturities, where

\footnotetext{
${ }^{23}$ This paper does not address whether this is the optimal methodology for STRIPS data. The same methodology is maintained to facilitate comparisons between STRIPS yields and those of notes and bonds.
} 
there are little data. In contrast, the N/B standard errors at the short end of the yield curve are below those from the STRIPS curve. This likely reflects that there is a large number of notes and bonds in that maturity range, and that the idiosyncratic variation of STRIPS yields, which is most prevalent among short-term STRIPS, reduces the precision of the STRIPS estimates. Lastly, both sets of standard errors surge higher at long-term maturities as the data become sparce.

The bottom panel compares the standard errors for the estimated forward rates. Again, the standard errors from the N/B estimates are as low as those from the STRIPS estimates at short maturities but are noticeably elevated at intermediate maturities. In general, the standard errors tend to increase in maturity. The reason is that the forward rate at a given horizon is determined by the yields on all outstanding securities with maturities beyond that horizon, so that fewer and fewer securities become informative about the forward rate as the horizon increases.

Figure 11 compares the estimated yields and forward rates from the N/B results and the STRIPS results over the entire sample. As evident, the yields and forward rates generally move in a similar pattern. In fact, the yields and forward rates are largely indistinguishable, except for the ten-year maturity. The differences in these lines are shown in Figure 12. The two- and twenty-five-year maturities have fairly limited deviations over the sample. However, more substantial differences are found at intermediate maturities. The ten-year N/B yield is consistently below the ten-year STRIPS yield over the sample and dropped significantly below it over the second half of 1998. Evidently, the turbulence in financial markets at that time increased the dispersion across the yields of individual Treasury securities, including larger premiums for more liquid securities, causing the difficulties highlighted above for the N/B estimates to intensify. However, the persistent differences before that time suggest that these difficulties affect the results through much of the sample.

Overall, the yield curves and forward rates estimated from coupon STRIPS are largely consistent with those estimated from notes and bonds, with the notable exception of intermediate maturities. Differences in this maturity range appear to be largely driven by difficulties in estimating the yield curve from notes and bonds. In general, using coupon STRIPS to estimate the yield curve appears to have some advantages over relying strictly on notes and bonds. The yields and forward rates estimated from STRIPS appear to have more plausible shapes, particularly at intermediate maturities where there are few notes and bonds available. Moreover, the results are estimated more precisely at all maturities except for the short end of the yield curve.

\section{$5 \quad$ Factors Affecting Individual Notes and Bonds}

Some of the above results have been affected by various "idiosyncratic" factors that influence the yields of particular Treasury notes and bonds. This section uses the coupon STRIPS yield curve estimated above to measure the impact of some of these factors on Treasury yields. The section begins by describing these factors in more detail. ${ }^{24}$

\footnotetext{
${ }^{24}$ Dupont and Sack (1999) and Fabozzi and Fleming (2000) offer comprehensive overviews of the Treasury market that discuss some of the characteristics of the market underlying these factors.
} 
Liquidity. Some investors may be willing to pay a premium for the greater liquidity of particular securities, since this liquidity allows an investor to change his position in the security quickly and with little impact on its price. A liquidity premium is particularly evident in the on-the-run Treasury securities, or the most recently issued security in each maturity class. Trading activity in on-the-run securities, which are frequently used for hedging and other trading-intensive purposes, far exceeds that of older, off-the-run Treasury securities. Indeed, over 34\% of the on-the-run tenyear note traded every day on average over 1998, while the percentages of the two- and five-year on-the-run issues trading daily were even higher. ${ }^{25}$ According to Fabozzi and Fleming (2000), $71 \%$ of the inter-dealer trading activity in all Treasury securities over 1998 was concentrated in the seven on-the-run issues. Because of the premiums that investors will pay for this liquidity, yields of on-the-run issues can at times fall well below the yields of off-the-run securities with similar maturities. In addition, the liquidity premium can affect the first several off-the-run issues as well, as the liquidity of those securities remains somewhat elevated even after new securities are issued.

Although there are some differences in liquidity across various STRIPS, these differences are more limited. No STRIPS has a level of liquidity that even approaches that of the on-the-run notes and bonds, and hence liquidity premiums do not present as large of a problem for estimating the yield curve from STRIPS data.

Specialness in the repo market. Treasury securities are often used as collateral in a repurchase agreement to obtain an overnight loan at the general collateral repo rate. However, particular Treasury securities often go "on special" in the repo market, meaning that these securities can be used as collateral to borrow at an overnight interest rate that is below the prevailing market rate. This situation frequently arises when there is a scarcity of the security in the repo market, either because there are a large number of market participants trying to borrow a particular security to cover short positions that they had established, or because the holders of a security do not make it available to the repo market. When a Treasury security is on special in the repo market, it will often trade at a premium to other securities, as investors are willing to purchase the security at a lower yield because they can use the security to borrow at the special repo rate. ${ }^{26}$ On-the-run securities frequently trade on special in the repo market, since there are a large number of short positions established around the auction of the security. However, specialness can arise from other factors, in which case differences in Treasury yields can arise for securities other than the on-the-run issues. STRIPS, of course, can also go on special in the repo market, particularly the hard-to-find securities at the shorter end of the STRIPS curve discussed above.

Cheapest-to-deliver for futures contracts. Futures on Treasury securities offered by the Chicago Board of Trade (CBOT) have become extensively traded. As of June 1999, trading volume in long bond futures alone had reached an average of 366,913 contracts per day, with each contract

\footnotetext{
${ }^{25}$ Based on author's calculation using trading volumes reported by Fabozzi and Fleming (2000), who use trading activity through inter-dealer brokers reported by GovPX.

${ }^{26}$ Duffie (1996) provides a discussion and model of the repo market, including the relationship between repo rates and Treasury yields.
} 
representing a Treasury security with $\$ 100,000$ face value, while open interest in those futures stood at 670,168 contracts at that time. The CBOT offers similar contracts on Treasury notes with two, five, and ten years to maturity. Each of these contracts allow a range of Treasury securities to be delivered, with the eligible securities defined according to their original and remaining maturities. One of the securities eligible for delivery will be the cheapest-to-deliver (CTD), meaning that the cost to the seller of the futures contract of purchasing the required amount of the security to deliver is the lowest for that security. ${ }^{27}$ The CTD security is often traded more actively than other off-therun issues, in part because market participants use that security to hedge their futures position. Because of its greater liquidity and (to a lesser extent) because some market participants may need to purchase the security to make delivery into the futures contract, the CTD may trade at a premium to other off-the-run securities with similar liquidity.

As yields have fallen on balance over recent decades, the prices of outstanding Treasury securities have generally increased, and by more for securities with longer duration. As a result, the cheapestto-deliver security for the bond contract has often been the $11 \frac{1}{4} \%$ February 2015 bond, which has the shortest maturity of all eligible securities (this is the issue just to the right of the maturity gap that was highlighted above). For example, from the beginning of 1998 through the end of the sample, that security was the cheapest to deliver into the upcoming futures contract on 283 of the 301 days. However, the CTD security can vary both through time and across contracts, thus affecting the yield curve unpredictably through time. Of course, there are no futures contracts affecting the yields on coupon STRIPS.

Premiums from par. Many Treasury securities are trading at considerable premiums to their par values as a result of the general decline in interest rates over recent decades. Anecdotal evidence suggests that some investors are reluctant to hold securities trading at large premiums to par. Some market participants claim that there are institutional factors that make it less appealing to hold a security that is expected to have capital losses, even though those losses are offset by higher coupon payments. Among securities trading at considerable premiums to par are the outstanding twenty-year bonds, which were issued more than a decade ago. STRIPS, on the other hand, all trade at a discount to par.

Supply. In many models the supply of a Treasury security should have no effect on its price. However, other models allow the demand schedules for individual securities to have some elasticity, for example if investors have heterogeneous preferences as in the preferred habitat theory of the term structure. In that case, a small supply of an individual security could potentially increase its price (depending on the availability of substitutes). At the same time, supply is an important determinant of liquidity. Securities with small issue sizes tend to be less liquid, which could instead push its price lower than other securities.

\footnotetext{
${ }^{27}$ The prices of eligible securities differ simply because of differences in coupon rates. To adjust for this effect, the CBOT contract scales the invoice amount-or the amount that the holder of the futures contract must pay upon receiving an eligible security-by a conversion factor that would give each security the same price if the yield curve were flat at $8 \%$. This notional coupon was switched to $6 \%$ beginning with the March 2000 contract.
} 
An active STRIPS market has some interesting implications for such supply issues. The ability to strip and reconstitute Treasury securities makes supply endogenous, at least to some extent, across the markets for STRIPS and for the underlying notes and bonds. If a restriction in the availability of an individual STRIP were to cause the price of that security to rise, investors could simply create additional supply by stripping more securities. The other STRIPS generated in the process could either be sold or used to reconstitute a shorter-term Treasury note or bond. Similarly, if a note or bond were in tight supply, investors could reconstitute that security if the corresponding STRIPS were available. Although it seems that this endogeneity of supply might limit any impact on prices, some shorter-term coupon STRIPS have at times moved well below the yield curve, as shown above, reportedly because of their scarcity. Whether supply effects are also observed across notes and bonds is not immediately obvious and must be answered empirically.

To explore the impact of these factors, the following exercise measures the idiosyncratic component of the yield on an individual Treasury security by comparing its yield to that of a "synthetic" security created from the estimated STRIPS yield curve. More specifically, using the zero-coupon yield curve estimated from Treasury coupon STRIPS (from section 4.3), a portfolio of zero-coupon securities is created to exactly replicate the payments of the underlying Treasury security. As argued above, because of the fungibility of coupon STRIPS, the value of the synthetic security should not be affected by any factor that is specific to the underlying note or bond. Thus, the deviation between the yield of the underlying security and the yield of the synthetic security provides a measure of the idiosyncratic component of the security's yield.

The calculation is performed on all outstanding Treasury notes and bonds on a daily basis over the sample, for a total of 202,809 observations. ${ }^{28}$ Some snapshots of the results are shown in Figure 13. In the top two panels, the yields predicted by the synthetic securities line up closely with the actual yields. However, some of the idiosyncratic factors described above clearly had an effect on the more recent date shown in the bottom panel.

Table 2 describes the results over the entire sample. As shown in the first line of the table, the average deviation between the yield of a Treasury security and that of its synthetic security has been less than a basis point across all outstanding securities. Moreover, most of the distribution is contained in a fairly narrow range, with $90 \%$ of the observations falling between -9 and 8 basis points. ${ }^{29}$ The remainder of the table explores the impact of the factors listed above on the yields of particular securities, looking at the idiosyncratic yield component of recently issued securities, cheapest-to-deliver securities, twenty-year bonds, securities trading at considerable premiums to par, and relatively small issues. ${ }^{30}$

The results indicate that there is no significant premium on the two- and five-year on-the-run

\footnotetext{
${ }^{28}$ Callable issues and securities with less than thirty days to maturity have been excluded.

${ }^{29} \mathrm{~A}$ portion of this variation arises from the noise in the data that generated some dispersion in the arbitrage relationship between STRIPS and notes and bonds shown in Figure 2.

${ }^{30}$ In the results presented, the cheapest-to-deliver security is assumed to be the $11 \frac{1}{4} \%$ February 2015 bond throughout the sample. As discussed above, this security was the CTD at least over a large portion of the sample. More complete data on the CTD security, such as the CTD issues on other futures contracts, are difficult to collect. Other factors, such as repo market specialness, are excluded because of the difficulty in obtaining data.
} 


\section{Table 2: Idiosyncratic Yield Components}

Yield Spread (in Basis Points) between the Treasury Note or Bond and a Synthetic Security Derived from the Estimated Coupon STRIPS Yield Curve that Replicates Its Payments

\begin{tabular}{|c|c|c|c|c|}
\hline & \multicolumn{2}{|c|}{ 1994:1 to $1999: 1$} & \multicolumn{2}{|c|}{ 1998:7 to $1999: 1$} \\
\hline & Average & $90 \%$ Interval & Average & $90 \%$ Interval \\
\hline All Securities & -0.9 & $(-9.1,8.1)$ & 2.0 & $(-9.4,15.4)$ \\
\hline Two-year Notes & & & & \\
\hline On-the-run & -0.9 & $(-8.3,4.1)$ & -7.0 & $(-18.4,0.4)$ \\
\hline 1st off-the-run & 0.6 & $(-5.9,5.1)$ & -2.9 & $(-8.3,2.1)$ \\
\hline 2nd off-the-run & 1.3 & $(-4.0,6.0)$ & -0.4 & $(-6.1,4.5)$ \\
\hline Five-year Notes & & & & \\
\hline On-the-run & -1.5 & $(-14.6,3.9)$ & $-13.5^{* *}$ & $(-23.2,-3)$ \\
\hline 1st off-the-run & 0.6 & $(-6.4,5.0)$ & -5.7 & $(-13.0,0.1)$ \\
\hline 2nd off-the-run & 1.0 & $(-5.5,5.2)$ & -2.7 & $(-9.8,2.4)$ \\
\hline Ten-year Notes & & & & \\
\hline On-the-run & $-13.9^{* *}$ & $(-23.4,-7.4)$ & $-22.6^{* *}$ & $(-33.5,-13.2)$ \\
\hline 1st off-the-run & $-9.3^{* *}$ & $(-17.1,-3,4)$ & $-16.2^{* *}$ & $(-27.6,-9.4)$ \\
\hline 2nd off-the-run & -6.2 & $(-13.3,3.0)$ & $-10.6^{* *}$ & $(-19.6,-2.7)$ \\
\hline Thirty-year Bonds & & & & \\
\hline On-the-run & $-8.1^{* *}$ & $(-20.8,-2.0)$ & $-18.0^{* *}$ & $(-29.4,-6.2)$ \\
\hline 1st off-the-run & $-3.4^{* *}$ & $(-8.8,-0.4)$ & $-9.5^{* *}$ & $(-18.8,-2.7)$ \\
\hline 2nd off-the-run & -1.8 & $(-4.2,0.3)$ & $-3.3^{* *}$ & $(-6.2,-1.2)$ \\
\hline Cheapest-to-Deliver & $-3.9^{* *}$ & $(-10.1,-0.8)$ & $-10.2^{* *}$ & $(-15.4,-4.8)$ \\
\hline Twenty-year Bonds & 0.5 & $(-6.2,5.4)$ & 3.6 & $(-2.1,9.1)$ \\
\hline Premium above $30 \%$ & -0.3 & $(-5.0,4.2)$ & -0.2 & $(-7.5,6.3)$ \\
\hline Issue Size below $\$ 5$ Bil. & 0.3 & $(-6.4,5.3)$ & 3.3 & $(-2.0,8.9)$ \\
\hline
\end{tabular}

** indicates significance in that the interval containing $90 \%$ of the observations does not span zero 
issues. However, the on-the-run ten-year note and thirty-year bond both have considerable liquidity premiums, falling about 14 and 8 basis points below the yield curve, on average. ${ }^{31}$ Moreover, those liquidity premiums also spilled over into the first off-the-run issues. The cheapest-to-deliver security is also found to have a significant premium, falling 4 basis points below the yield curve on average. In contrast, there is no significant evidence that twenty-year bonds or securities trading at large premiums deviated from the yield curve. Similarly, size does not appear to be an important factor in generating idiosyncratic yield movements.

As shown in the right-hand columns, these idiosyncratic premiums intensified over the second half of 1998 and into 1999. Liquidity premiums became more evident in the two- and five-year notes, and the premiums on the ten- and thirty-year securities increased sharply. Moreover, significant liquidity premiums extended through the second off-the-run issues for the ten- and thirty-year securities. Similarly, the premium on the cheapest-to-deliver security increased significantly. These patterns likely reflect an increase in the preference for liquidity following the turbulence in financial markets at that time. Consistent with that interpretation, the less liquid twenty-year bonds moved 4 basis points above the yield curve on average, although that deviation is not significant judging from the $90 \%$ interval. As before, no effect can be identified for securities trading at large premiums or for small issue sizes.

\section{Conclusion}

Treasury coupon STRIPS provide a valuable source of information about the zero-coupon Treasury yield curve. The STRIPS market is highly integrated with the market for notes and bonds. Moreover, coupon STRIPS offer several advantages over notes and bonds for measuring the zero-coupon yield curve: they are already in the form of zero-coupon securities, they have a complete range of maturities, and their fungibility seems to remove some of the idiosyncratic variation found in the yields of notes and bonds.

Given these advantages, the raw coupon STRIPS quotes themselves can be used to evaluate zero-coupon curves estimated from notes and bonds under various methods. The results indicate that one of the assumptions imposed by the Nelson-Siegel method-that longer-term yields and forward rates approach a constant level — is consistently violated by the STRIPS yields. The FisherNychka-Zervos method, which (as implemented here) is a much more flexible specification, is more effective at capturing the overall shape of the STRIPS yields. However, at times this method leads to very erratic patterns of forward rates that appear to be related to the lack of data at intermediate maturities and various premiums affecting individual securities.

Applying the FNZ method directly to STRIPS instead results in more precise estimates of the zero-coupon yield curve and forward rates. Moreover, these curves are less erratic, suggesting that their shapes may reflect fundamental factors such as monetary policy expectations, risk premiums,

\footnotetext{
${ }^{31}$ These findings may reflect that the ten- and thirty-year securities were issued on a quarterly (or less) baseis over the sample, while the two- and five-year notes were issued monthly over parts of the sample. A more precise investigation of the liquidity premium would control for auction patterns and other factors.
} 
or interest-rate volatility as opposed to factors specific to individual securities.

The potential shortcoming of coupon STRIPS is that they have limited liquidity at shorter maturities. Indeed, the short end of the yield curve is the only portion where the standard errors of the estimated STRIPS yield curve exceed those of the yield curve estimated from notes and bonds. Considering this, a potentially promising approach may be to estimate the yield curve from a combination of quotes on coupon STRIPS and on notes and bonds. Indeed, coupon STRIPS could be used to fill in the maturity gap across notes and bonds, thereby eliminating some of the difficulties that arise, while notes and bonds could be used to determine the shorter end of the yield curve.

\section{References}

[1] Bank for International Settlements. 1999. Zero-Coupon Yield Curves: Technical Documentation.

[2] Daves, Phillip R. and Michael C. Ehrhardt. 1993. Liquidity, Reconstitution, and the Value of U.S. Treasury Strips. Journal of Finance 48, 315-329.

[3] Duffie, Darrell. 1996. Special Repo Rates. Journal of Finance 51, 493-526.

[4] Dupont, Dominique and Brian Sack. 1999. The Treasury Securities Market: Overview and Recent Developments. Federal Reserve Bulletin 85, 785-806.

[5] Fabozzi, Frank J. and Michael J. Fleming. 2000. U.S. Treasury and Agency Securities. In F. Fabozzi (ed.), The Handbook of Fixed Income Securities: 6th Edition. New York: McGraw Hill.

[6] Fisher, Mark, Douglas Nychka, and David Zervos. 1995. Fitting the Term Structure of Interest Rates with Smoothing Splines. Finance and Economics Discussion Series \#1995-1. Board of Governors of the Federal Reserve System.

[7] Fisher, Mark. 1996. Fitting and Interpreting the U.S. Yield Curve at the Federal Reserve Board. Mimeo, Federal Reserve Board of Governors.

[8] Fisher, Mark and David Zervos. 1996. YieldCurve. In H. Varian (ed.), Computational Economics and Finance: Modeling and Analysis with Mathematica. New York: Springer-Verlag.

[9] Livingston, Miles and Deborah Wright Gregory. 1989. The Stripping of U.S. Treasury Securities. Monograph Series in Finance and Economics \#1989-1, Salomon Brothers Center for the Study of Financial Institutions, New York University.

[10] Jordan, Bradford D., Randy D. Jorgensen, and David R. Kuipers. 2000. The Relative Pricing of U.S. Treasury STRIPS: Empirical Evidence. Journal of Financial Economics 56, 89-123. 
[11] Nelson, C. R. and A. F. Siegel. 1987. Parsimonious Modeling of Yield Curves. Journal of Business 60, 473-489.

[12] Svensson, Lars E. O. 1994. Estimating and Interpreting Forward Rates: Sweden 1992-4. National Bureau of Economic Research Working Paper \#4871. 
Figure 1: Amounts of Treasury Securities Outstanding
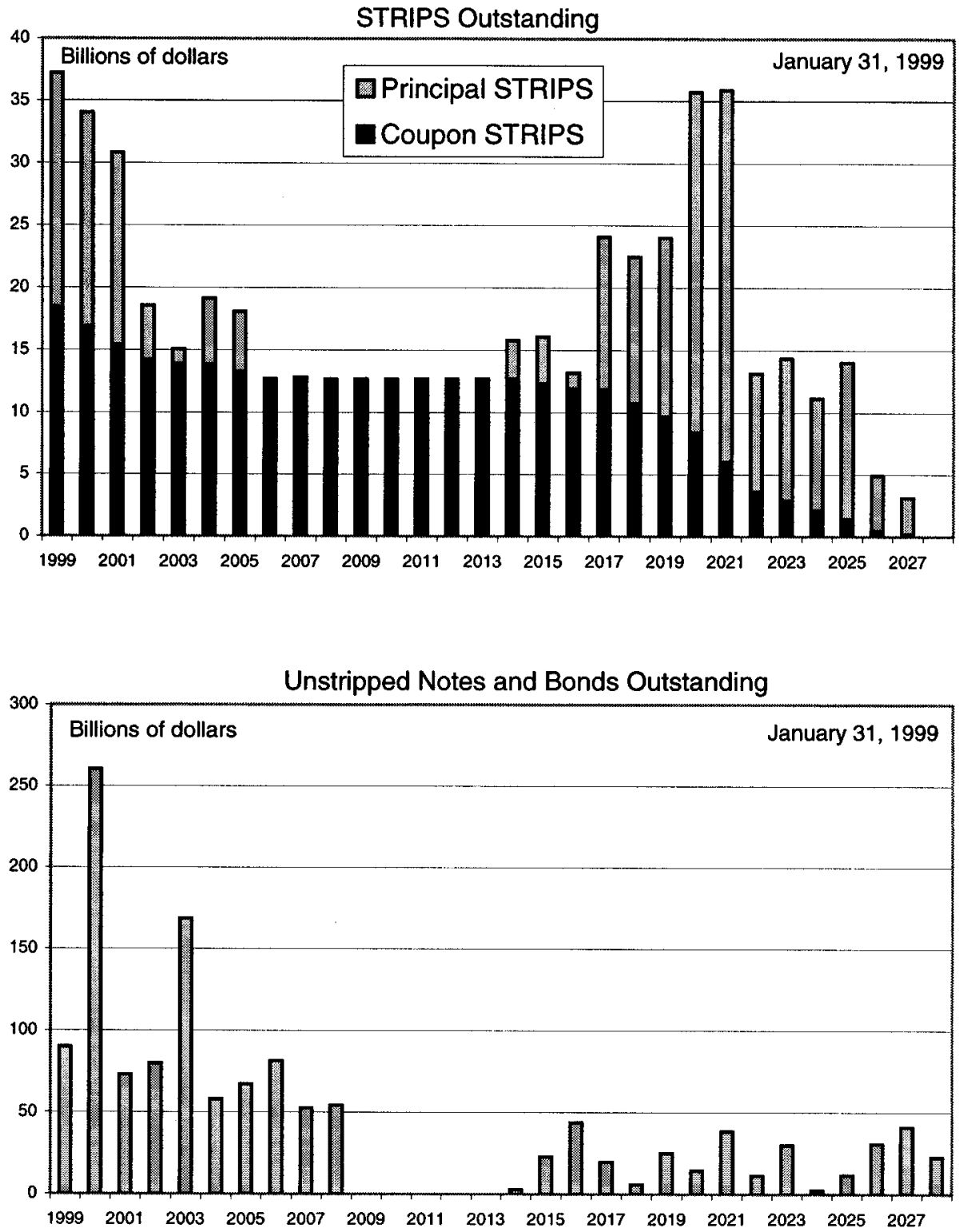
Figure 2: Histogram of Price Deviations between STRIPS and Notes/Bonds

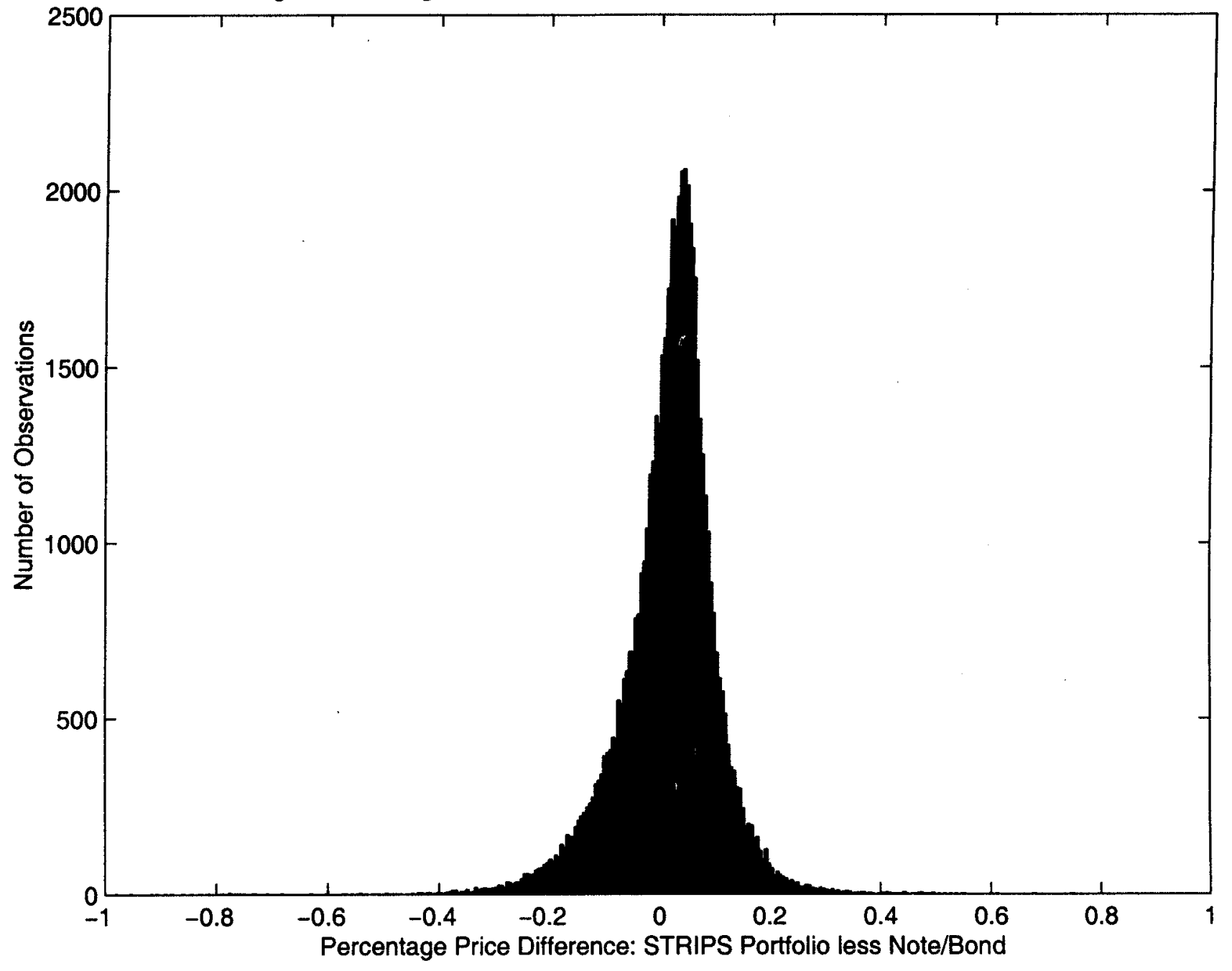


Figure 3: Principal and Coupon STRIPS Yields (12/15/98)
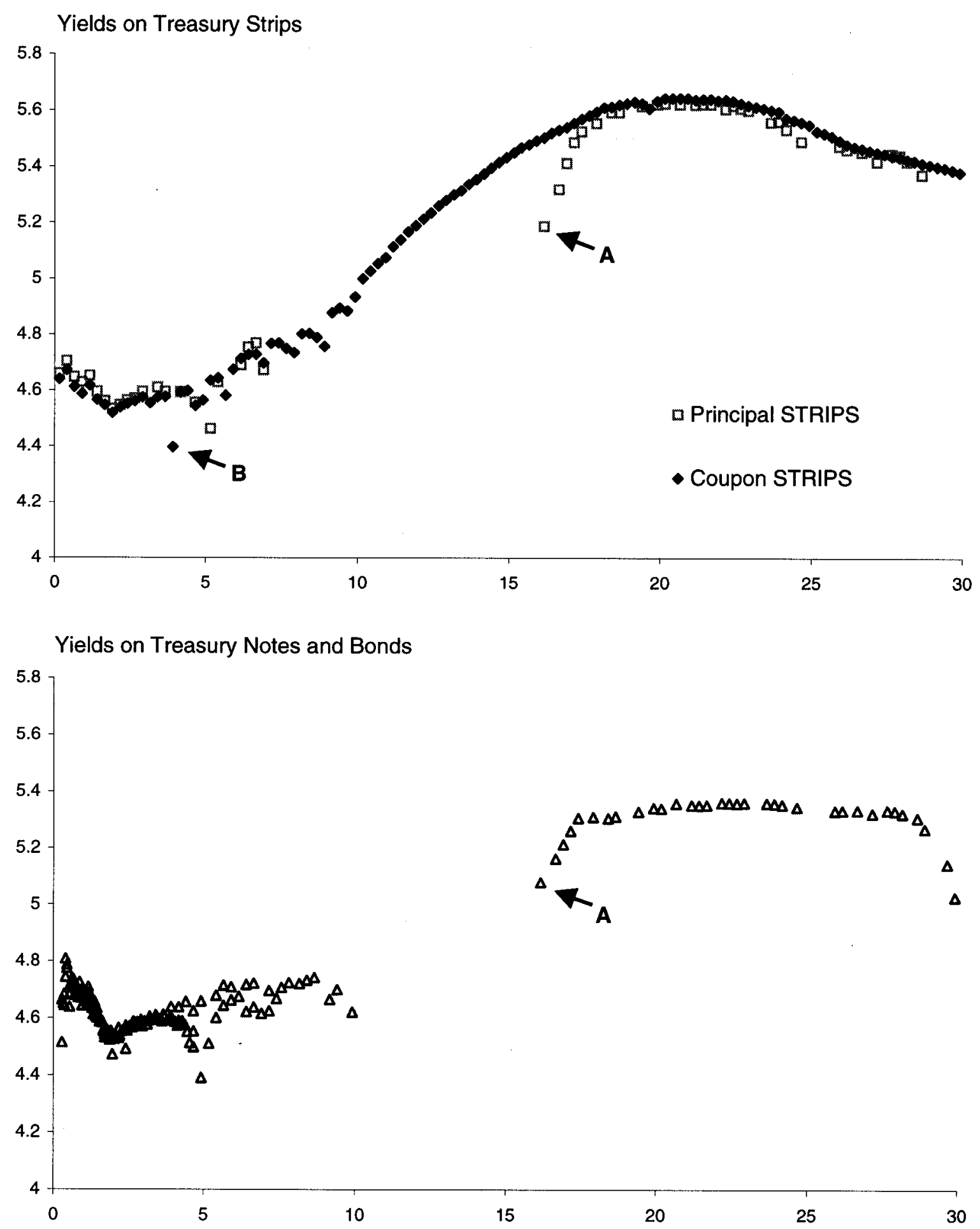
Figure 4: Deviations between Principal and Coupon STRIPS Prices

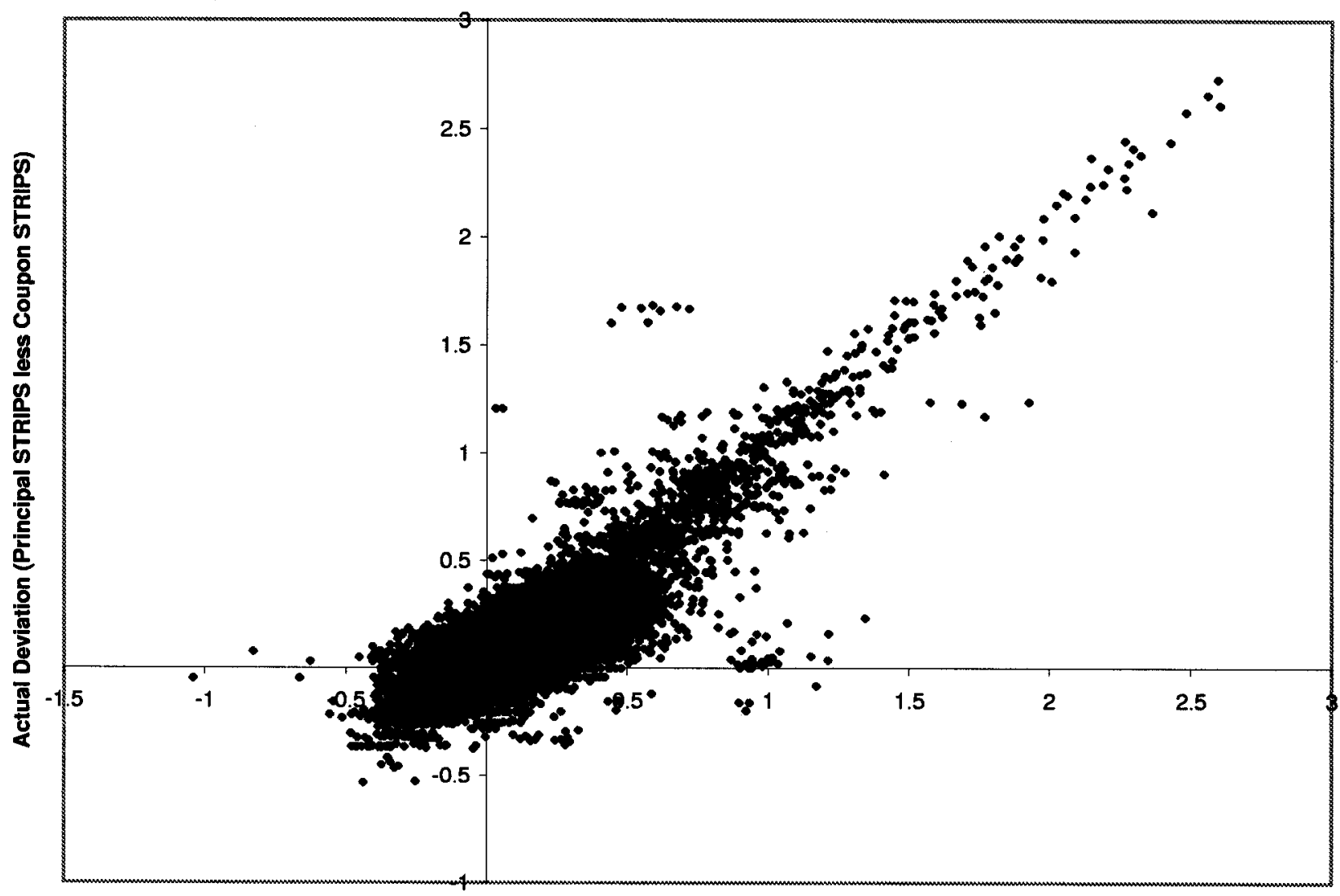

Deviation Needed for STRIPS Portfolio to Match Underlying Note/Bond 
Figure 5: Nelson-Siegel Method Compared to Coupon STRIPS

\section{Zero-Coupon Yield Curves}
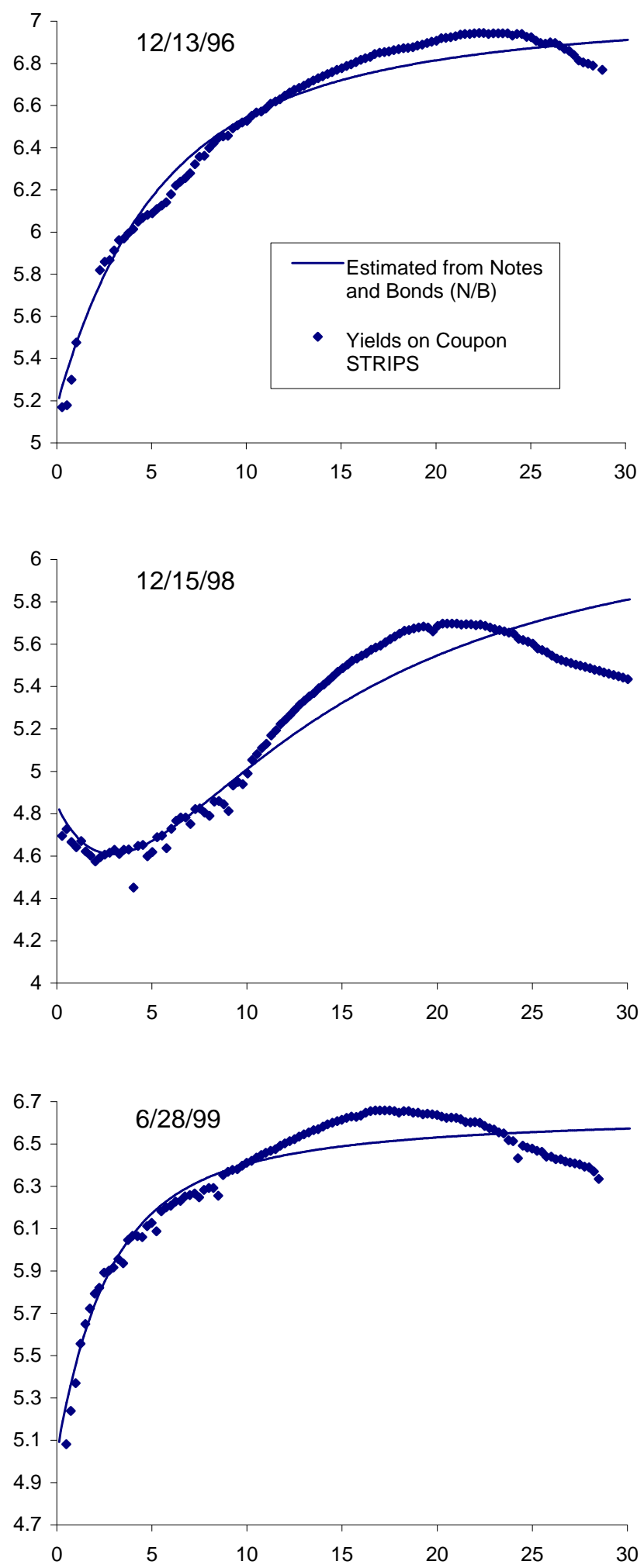

\section{Implied Forward Rates}
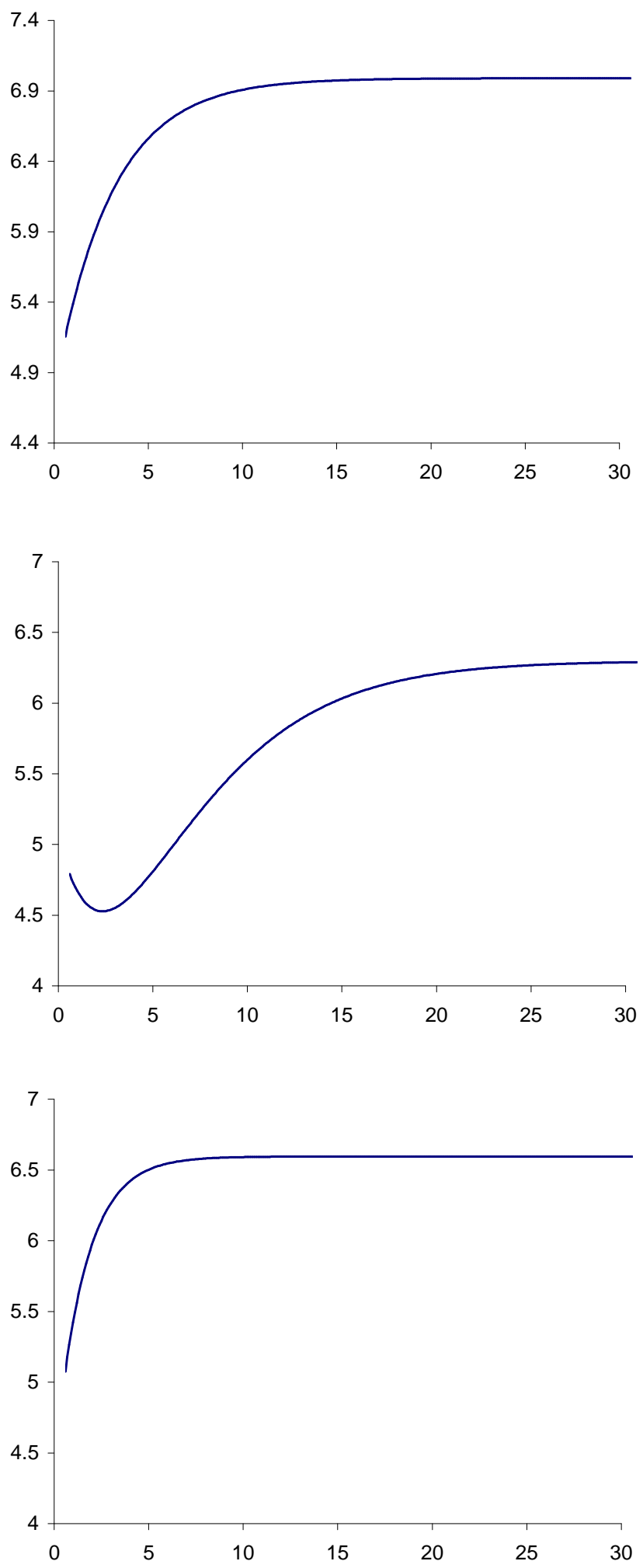

Yield curves are zero-coupon yields on a bond-equivalent basis; forward rates are instantaneous forward rates implied by zero-coupon yields. 
Figure 6: Fisher-Nychka-Zervos Method Compared to Coupon STRIPS

\section{Zero-Coupon Yield Curves}
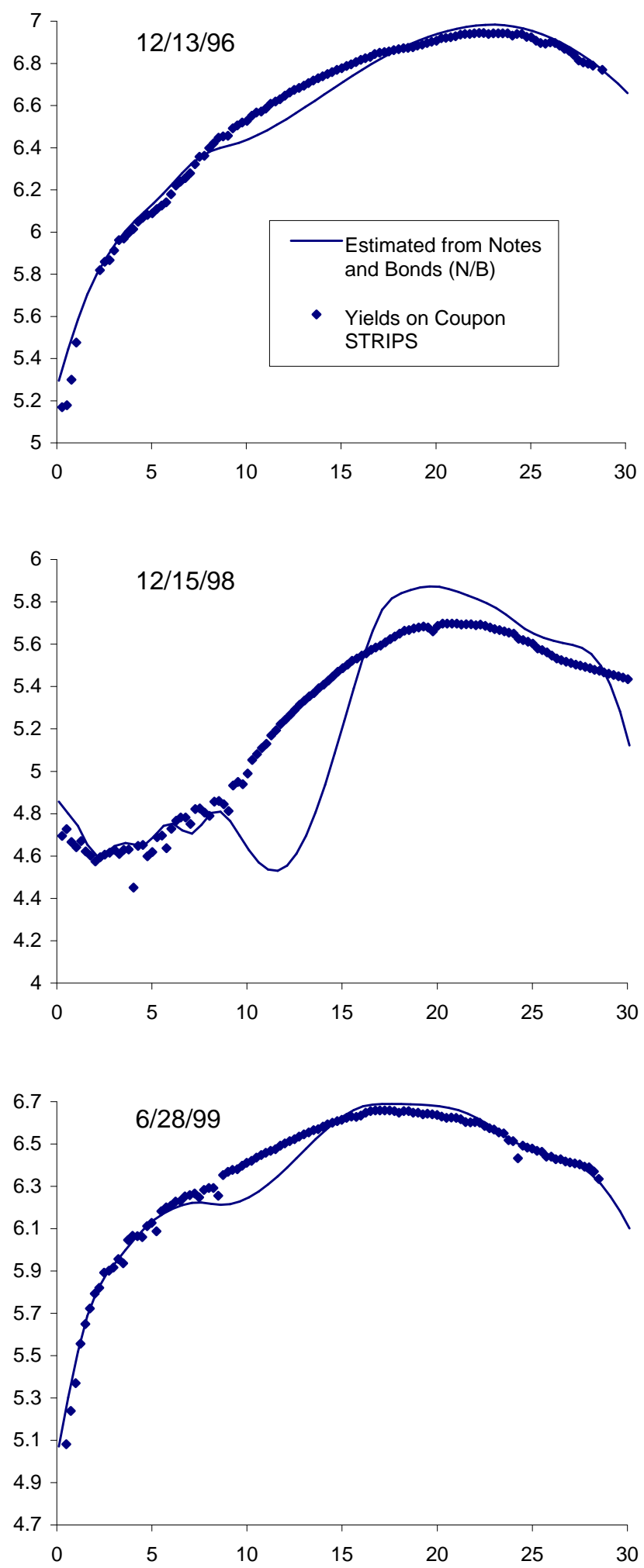

\section{Implied Forward Rates}
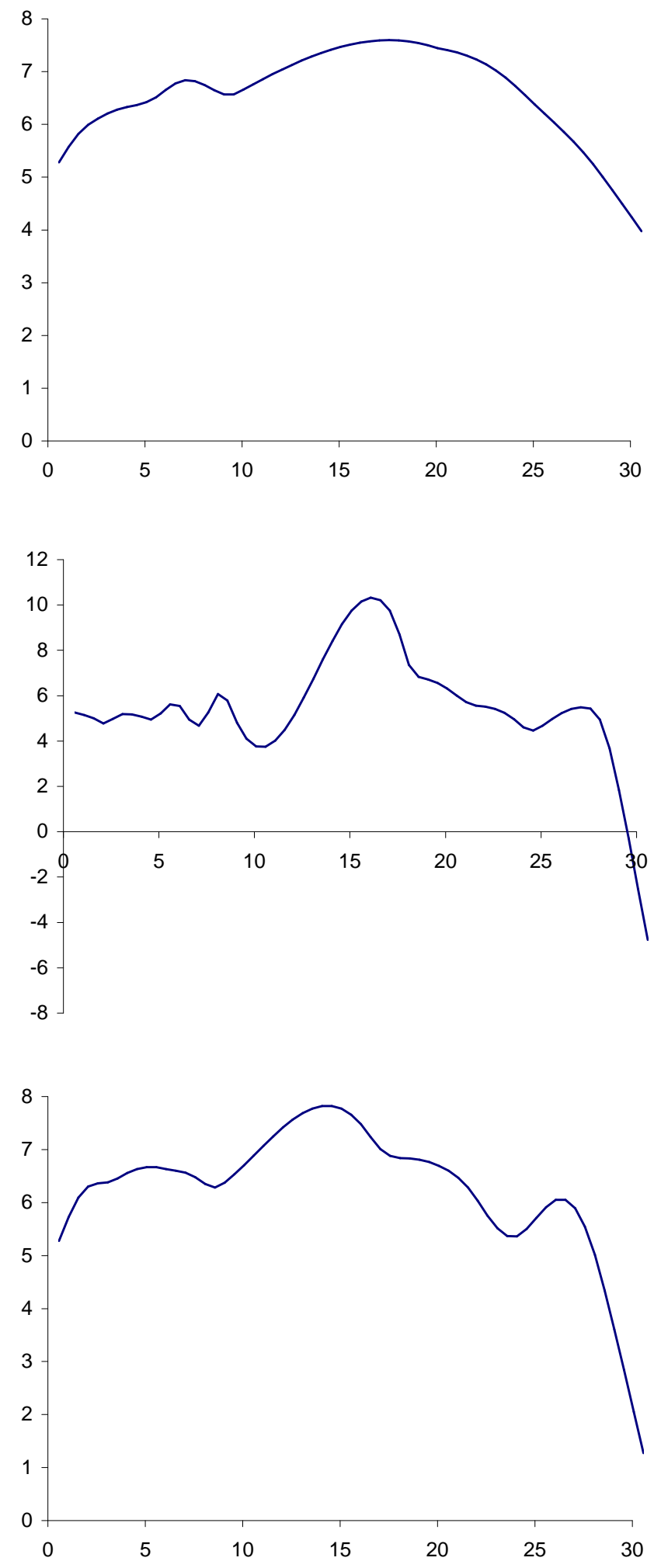

Yield curves are zero-coupon yields on a bond-equivalent basis; forward rates are instantaneous forward rates implied by zero-coupon yields. 
Figure 7: Zero-Coupon Yield Curve Estimated from Notes and Bonds (12/15/98)

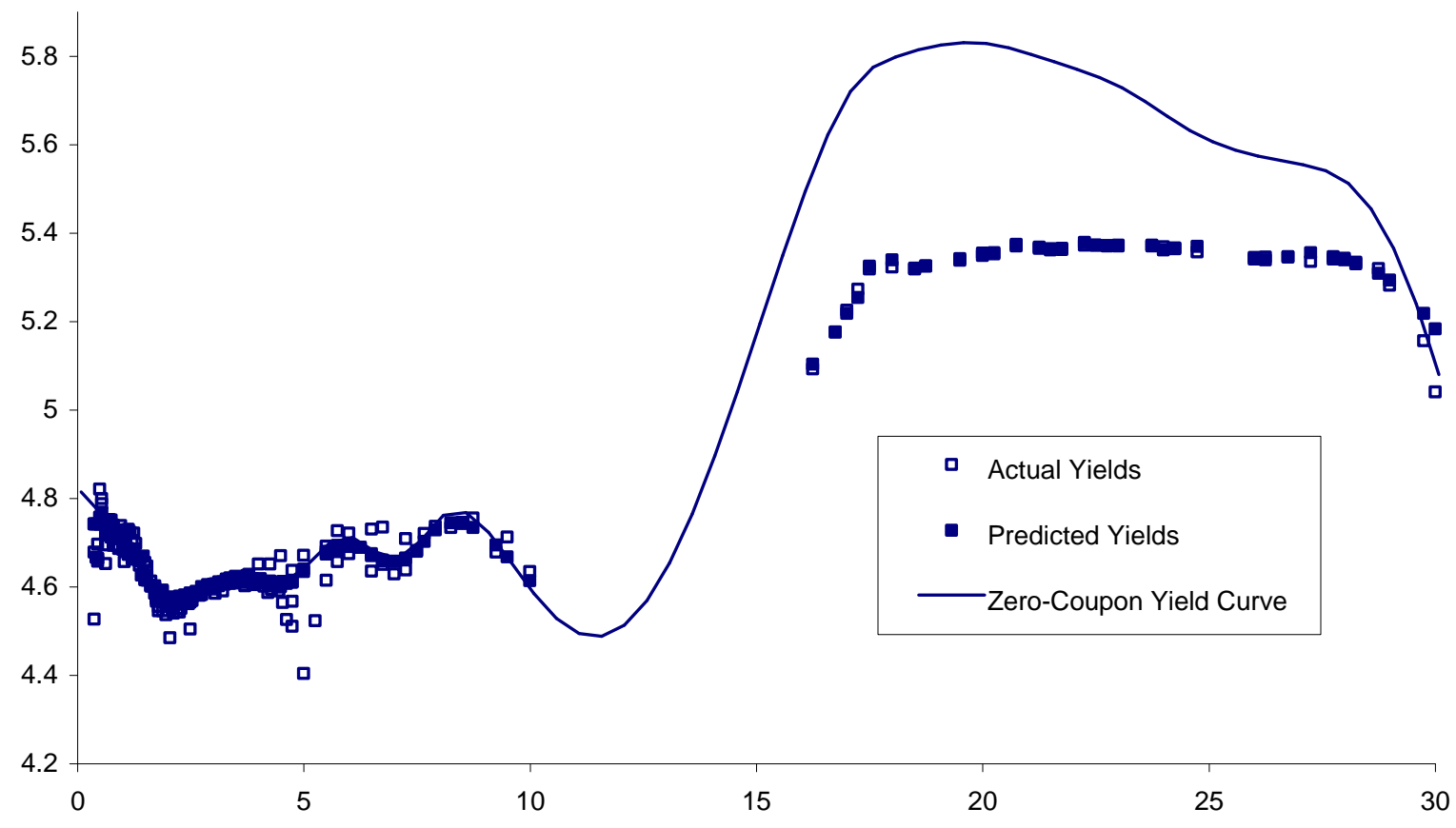


Figure 8: Effect of Removing Recently Issued Securities

\section{Zero-Coupon Yield Curves (6/28/99)}
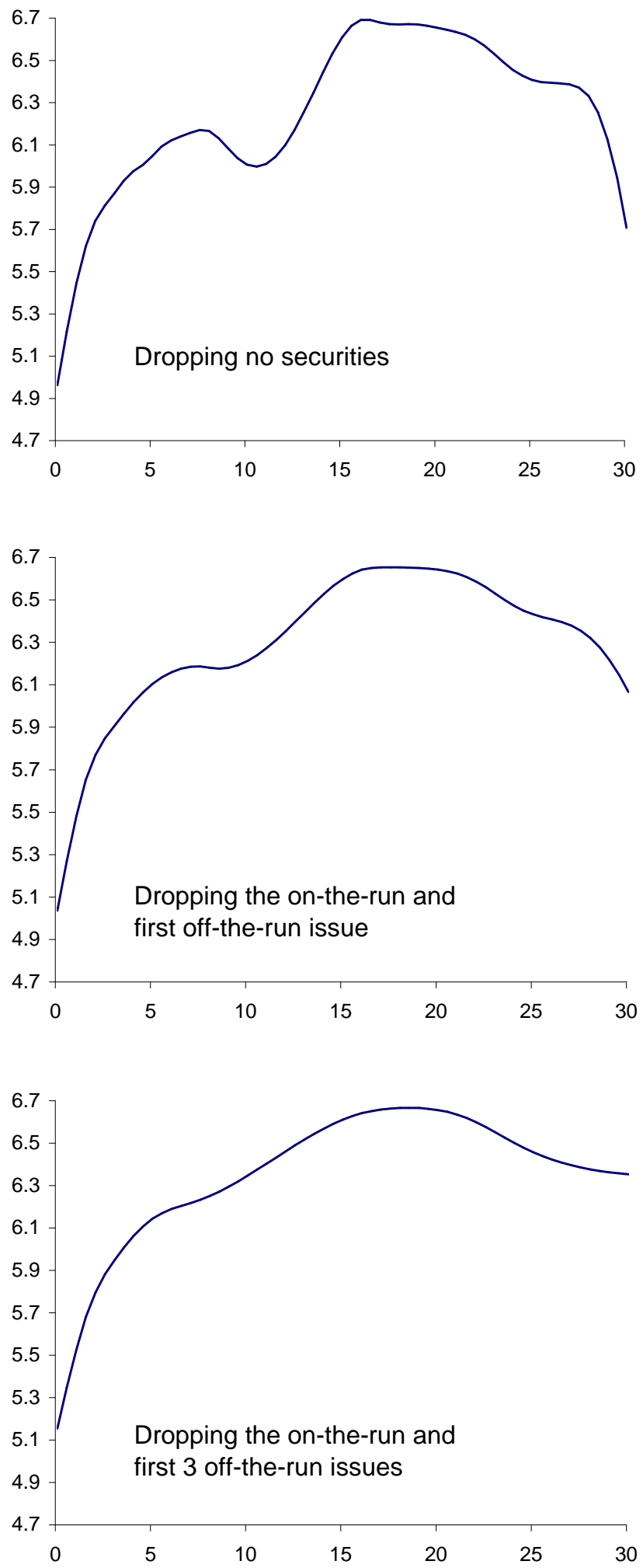

Implied Forward Rates (6/28/99)
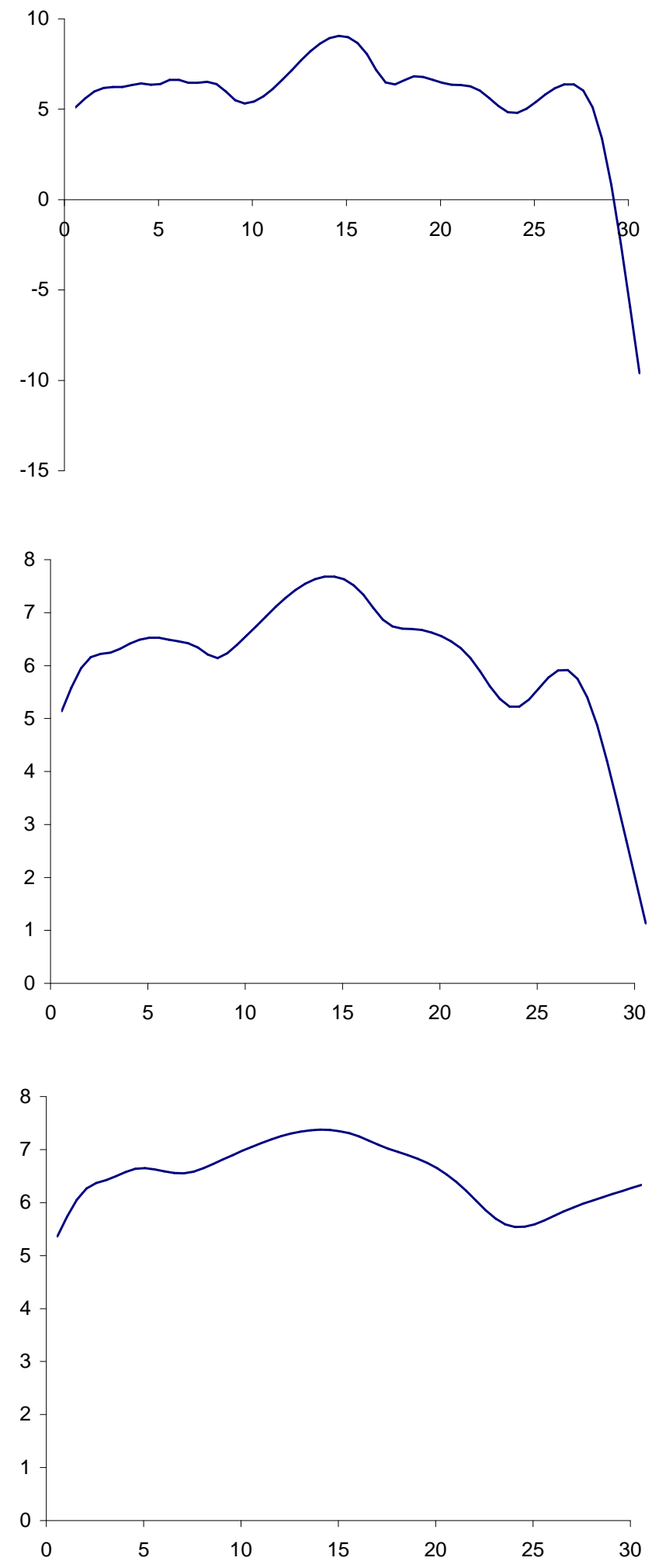

Yield curves are zero-coupon yields on a bond-equivalent basis; forward rates are instantaneous forward rates implied by zero-coupon yields. 
Figure 9: Estimation Results using Coupon STRIPS

Estimates from Notes and Bonds (6/28/99)

Actual Yields and Estimated Zero-Coupon

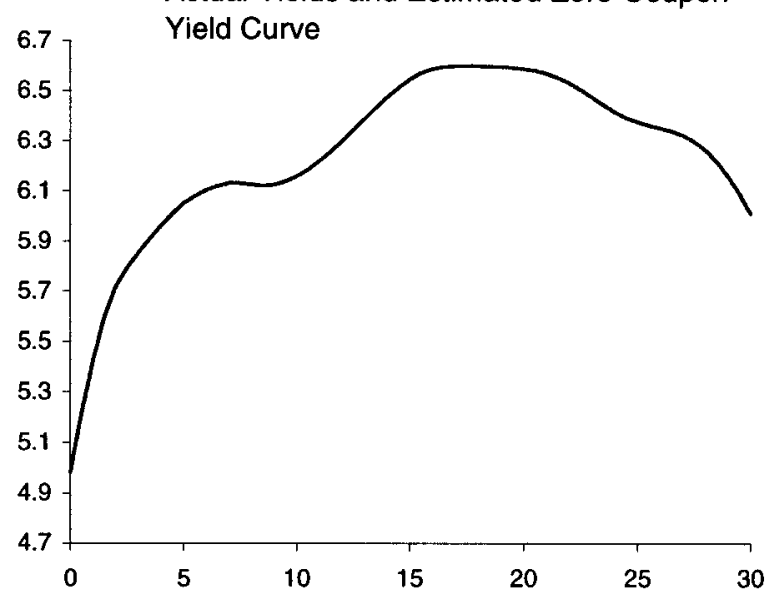

Estimated Zero-Coupon Yield Curve

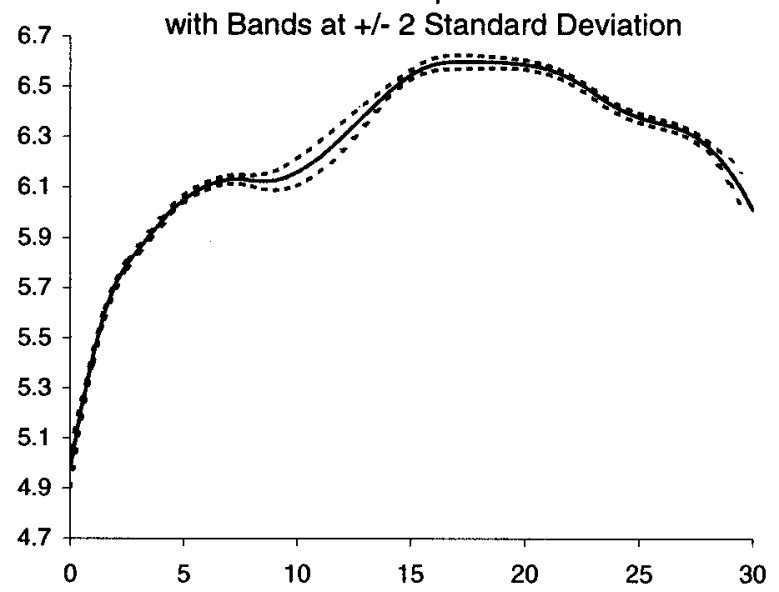

Estimates from Coupon STRIPS (6/28/99)
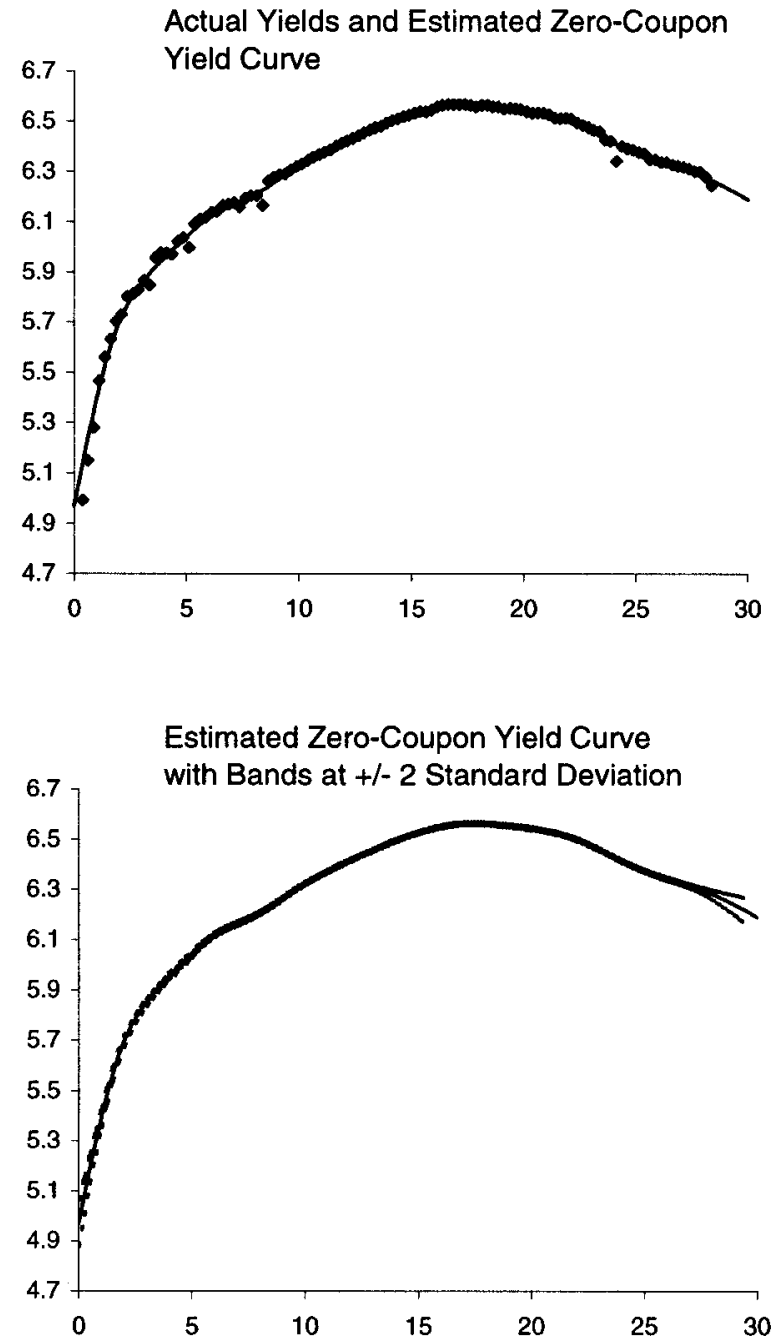

Estimated Forward Rates with Bands at +/- 2 Standard Deviation

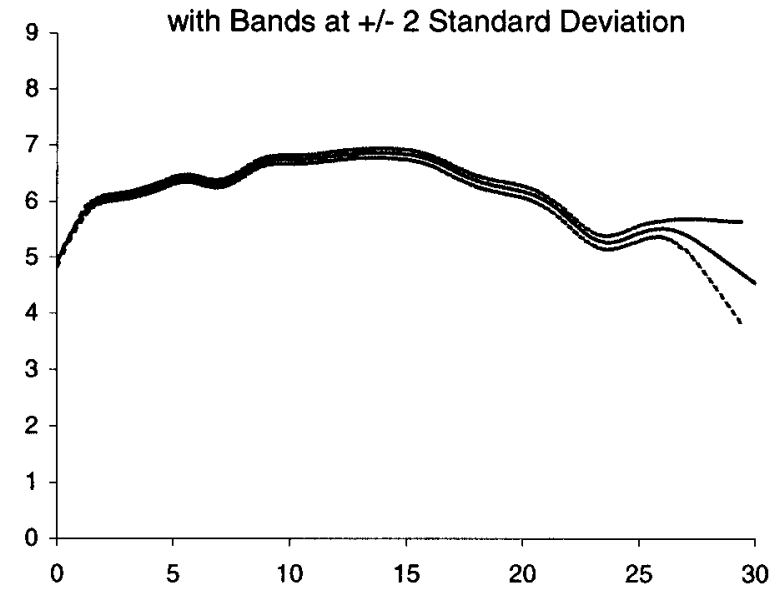

Yield curves are zero-coupon yields on a bond-equivalent basis; forward rates are instantaneous forward rates implied by zero-coupon yields. 
Figure 10: Precision of Estimates (6/28/99)
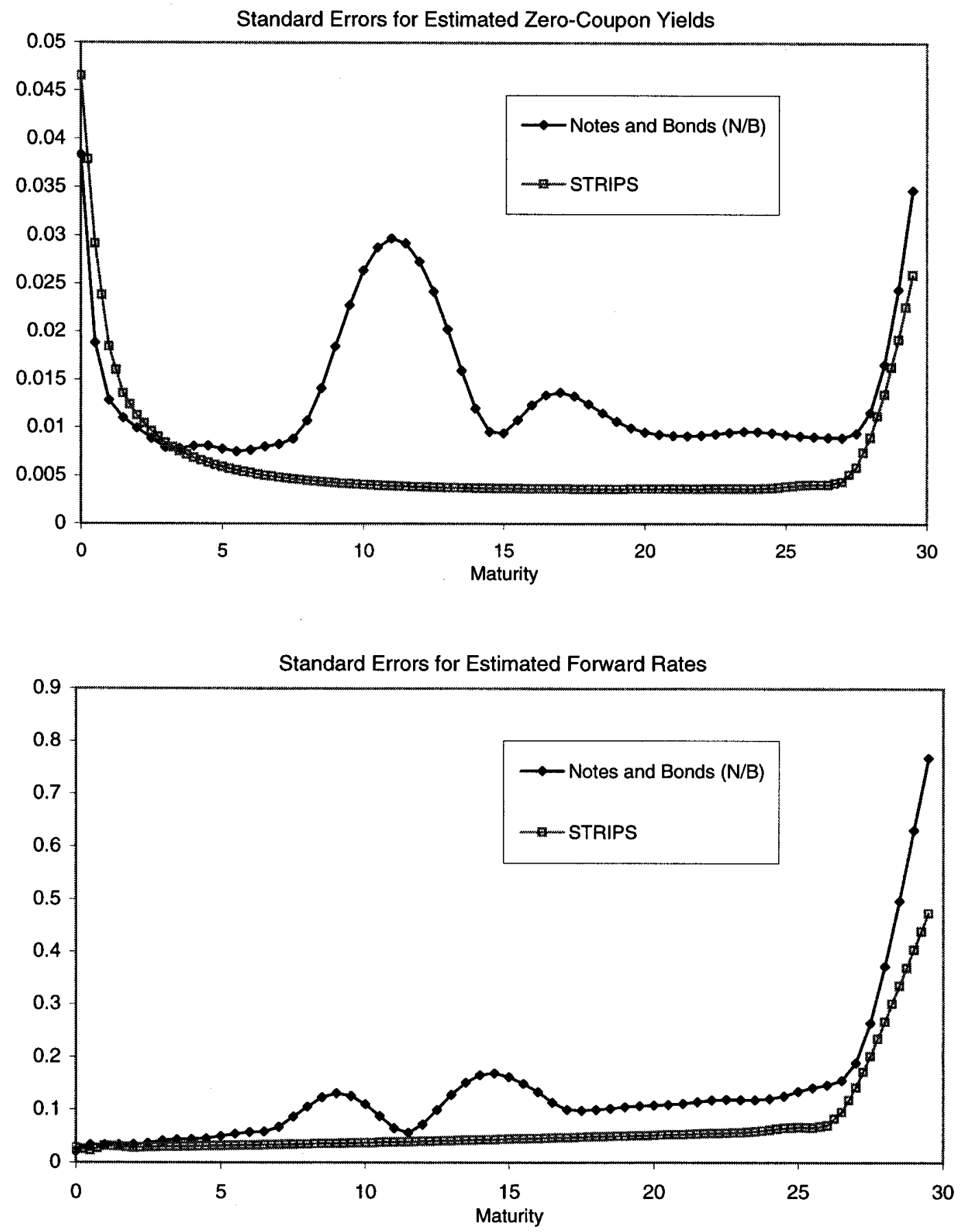

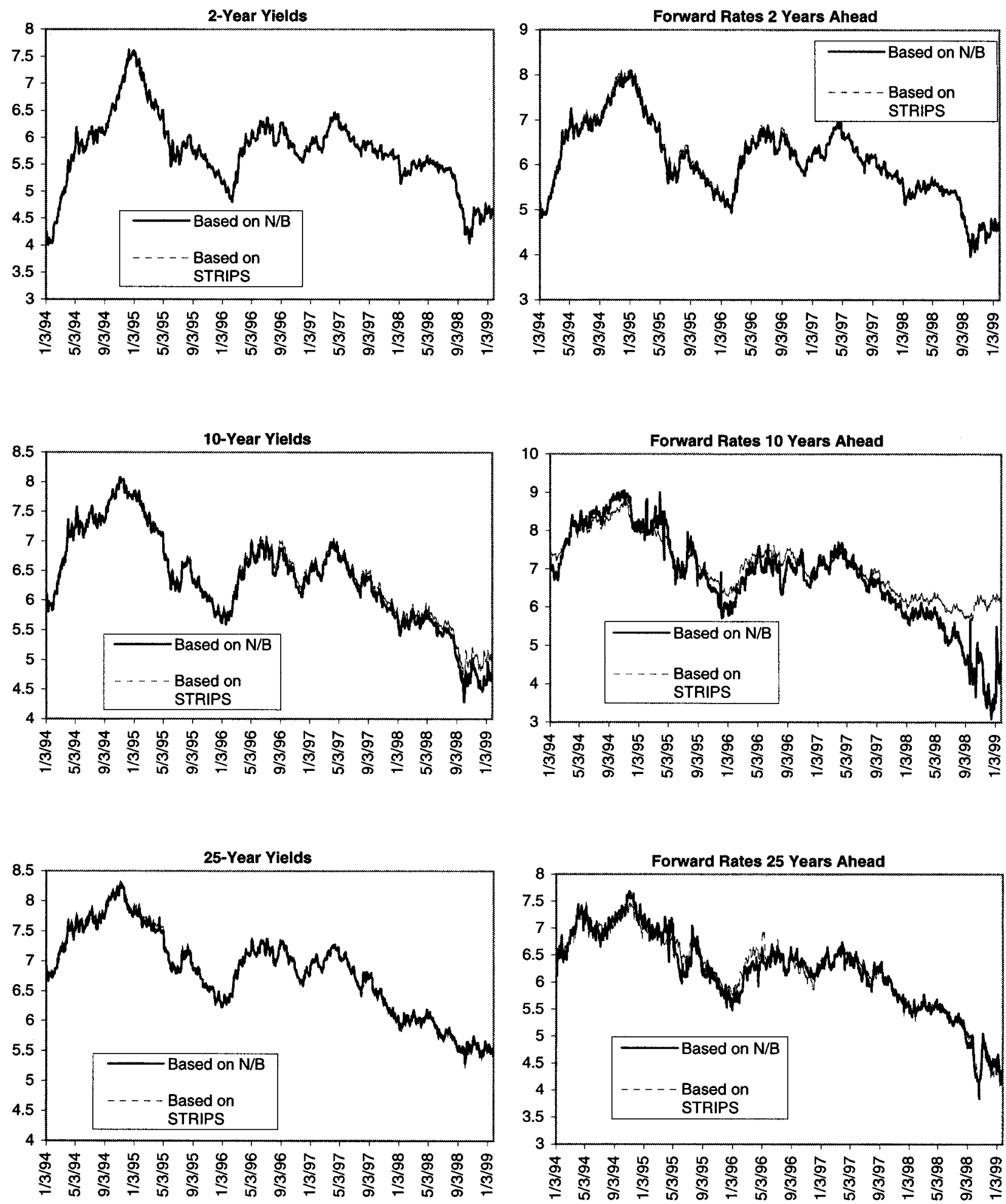
Figure 12: Differences in Yields and Forward Rates (N/B less STRIPS)
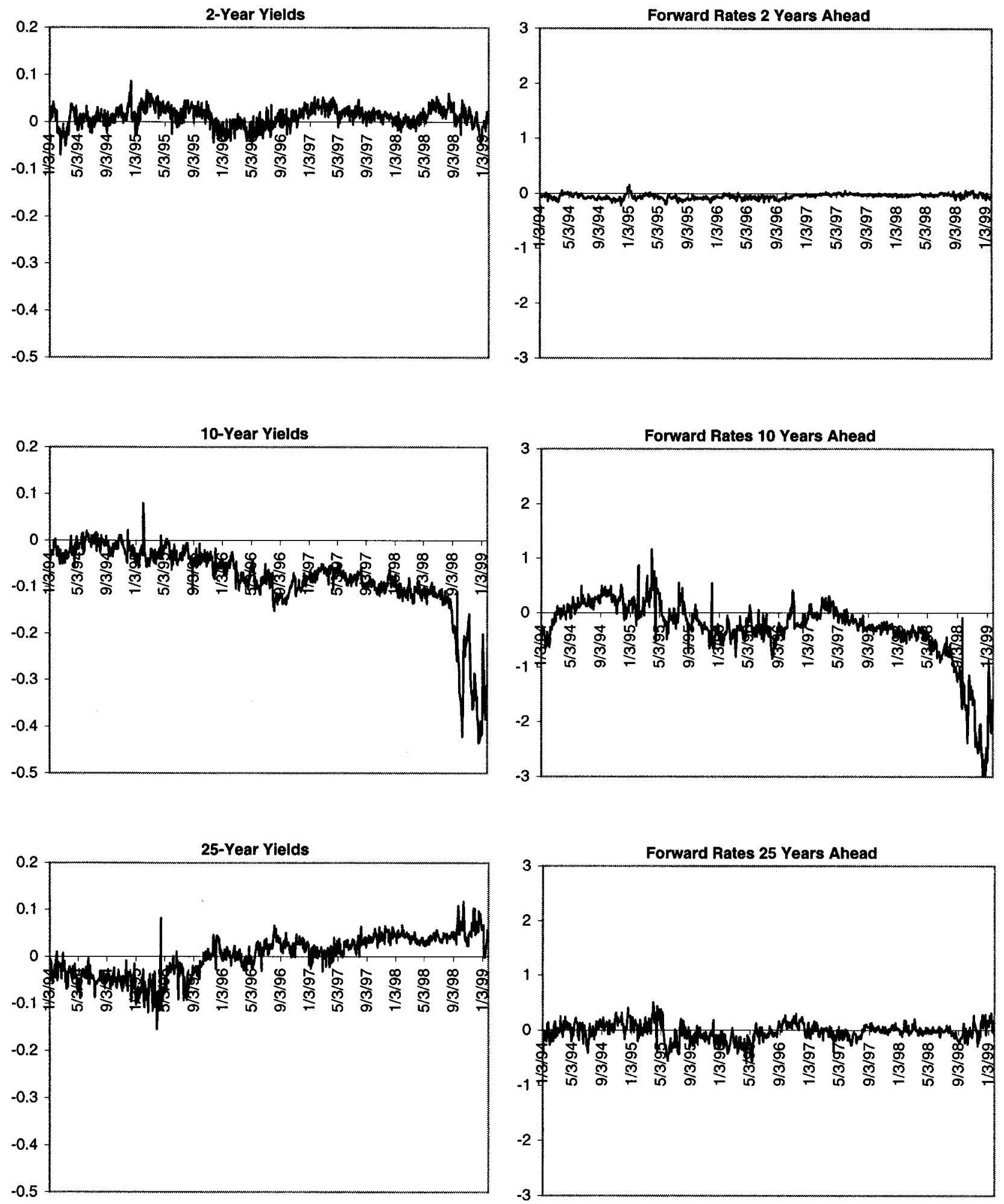

Yields are zero-coupon yields; forward rates are instantaneous forward rates implied by zero-coupon yields. 
Figure 13: Snapshots of Idiosyncratic Factors
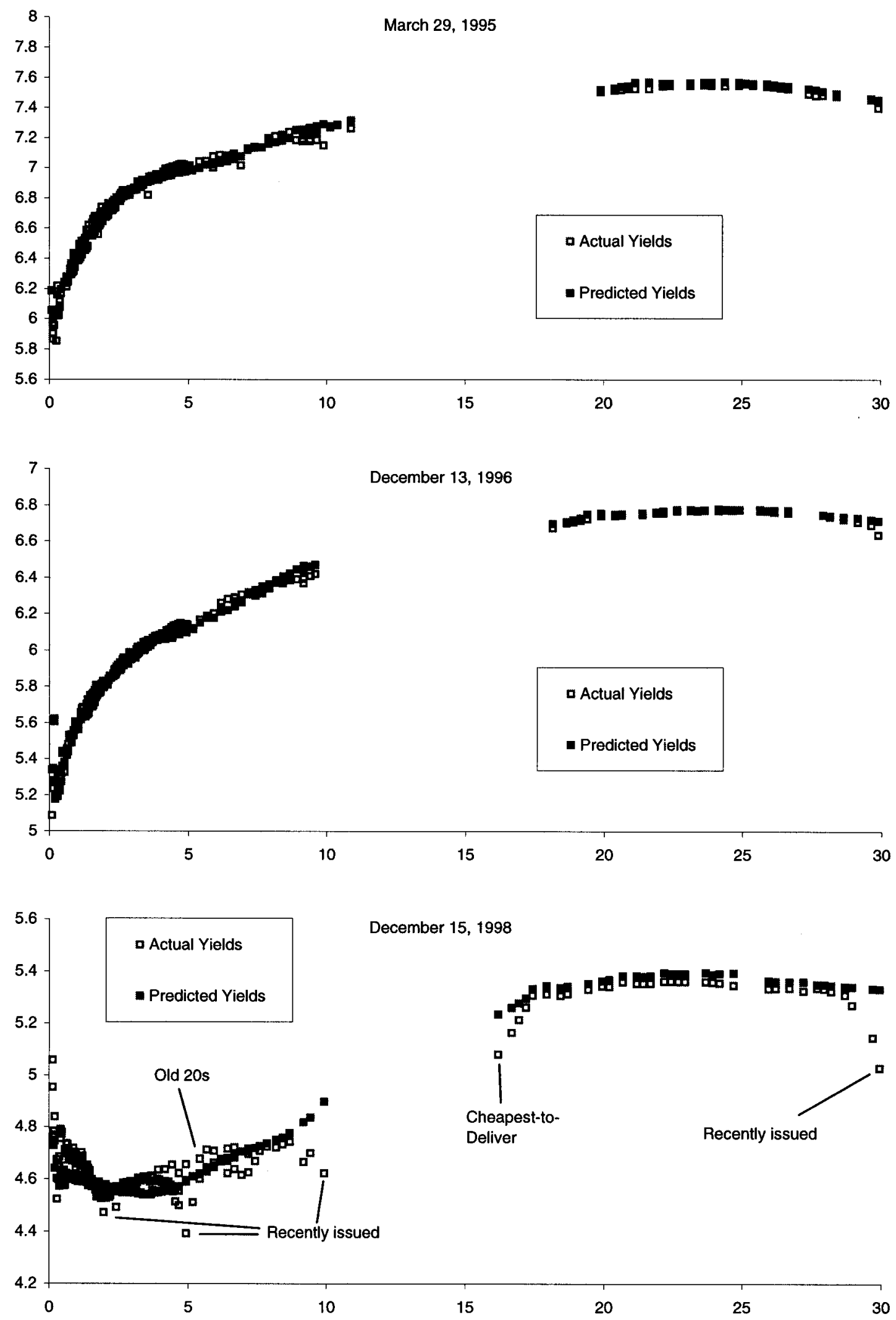